Oil \& Natural Gas Technology

DOE Award No.: DE-FC26-06NT15486

Reporting Period: October 2004 to June 2008

\title{
Final Report HIGH-POWER TURBODRILL AND DRILL BIT FOR DRILLING WITH COILED TUBING
}

\author{
Submitted by: \\ Technology International, Inc. \\ 2103 River Falls Drive \\ Kingwood, Texas 77339-3154 \\ bradtke@technologyinternationalinc.com \\ Prepared by: \\ Principal Investigator \\ Robert Radtke \\ David Glowka \\ Dr. Man Mohan Rai \\ NASA AMES Research Center \\ Project Manager \\ Dr. David Conroy \\ Tim Beaton \\ Rocky Seale \\ Joseph Hanna \\ Smith Neyrfor \\ Homer Robertson \\ Terra Tek Drilling Laboratory \\ Prepared for: \\ United States Department of Energy \\ National Energy Technology Laboratory
}

July 2011

Office of Fossil Energy

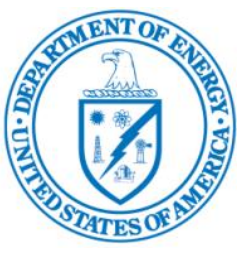




\section{Notice}

This report was prepared as an account of work sponsored by an agency of the United States Government. Neither the United States Government nor any agency thereof, nor any of their employees, makes any warranty, express or implied, or assumes any legal liability or responsibility for the accuracy, completeness, or usefulness of any information, apparatus, product, or process disclosed, or represents that its use would not infringe privately owned rights. Reference herein to any specific commercial product, process, or service by trade name, trademark, manufacturer, or otherwise does not necessarily constitute or imply its endorsement, recommendation, or favoring by the United States Government or any agency thereof. The views and opinions of authors expressed herein do not necessarily state or reflect those of the United States Government or any agency thereof. 


\section{Preface}

Dr. Steve Holditch, 2002 President of the Society of Petroleum Engineers, said, "To economically recover gas, we need to learn how to drill smaller boreholes more rapidly and less expensively." However, achieving this goal of increased drilling efficiency does not necessarily mean using a conventional rotary drilling rig. Coiled tubing units increasingly are being used to drill for oil and natural gas deposits at lower costs relative to the costs for using a conventional drilling rig and with a much smaller environmental footprint. In many applications, coiled tubing drilling can be a cost-effective alternative for drilling highly deviated wells or drilling new hole sections in existing wells.

The ability of a coiled tubing unit to achieve the drilling objectives for a well are often driven by the capabilities of the downhole motor or Turbodrill used to convert the hydraulic energy of the drilling fluid into mechanical energy for driving the drill bit. In the past, smaller diameter downhole motors and Turbodrills were designed primarily for workover and remedial operations and often lacked the power and downhole life characteristics necessary for more demanding drilling operations.

The purpose of this project was to demonstrate that the development of a more powerful high-speed Turbodrill and high-temperature drill bit will reduce the cost per foot drilled and expand the use of coiled tubing units for drilling purposes. 


\begin{abstract}
Commercial introduction of Microhole Technology to the gas and oil drilling industry requires an effective downhole drive mechanism which operates efficiently at relatively high RPM and low bit weight for delivering efficient power to the special high RPM drill bit for ensuring both high penetration rate and long bit life. This project entails developing and testing a more efficient 2-7/8 in. diameter Turbodrill and a novel 4-1/8 in. diameter drill bit for drilling with coiled tubing. The high-power Turbodrill were developed to deliver efficient power, and the more durable drill bit employed high-temperature cutters that can more effectively drill hard and abrasive rock. This project teams Schlumberger Smith Neyrfor and Smith Bits, and NASA AMES Research Center with Technology International, Inc (TII), to deliver a downhole, hydraulically-driven power unit, matched with a custom drill bit designed to drill 4-1/8 in. boreholes with a purpose-built coiled tubing rig.

The U.S. Department of Energy National Energy Technology Laboratory has funded Technology International Inc. Houston, Texas to develop a higher power Turbodrill and drill bit for use in drilling with a coiled tubing unit. This project entails developing and testing an effective downhole drive mechanism and a novel drill bit for drilling "microholes" with coiled tubing. The new higher power Turbodrill is shorter, delivers power more efficiently, operates at relatively high revolutions per minute, and requires low weight on bit. The more durable thermally stable diamond drill bit employs hightemperature TSP (thermally stable) diamond cutters that can more effectively drill hard and abrasive rock. Expectations are that widespread adoption of microhole technology could spawn a wave of "infill development" drilling of wells spaced between existing wells, which could tap potentially billions of barrels of bypassed oil at shallow depths in mature producing areas. At the same time, microhole coiled tube drilling offers the opportunity to dramatically cut producers' exploration risk to a level comparable to that of drilling development wells.
\end{abstract}

Together, such efforts hold great promise for economically recovering a sizeable portion of the estimated remaining shallow (less than 5,000 feet subsurface) oil resource in the United States. The DOE estimates this U.S. targeted shallow resource at 218 billion barrels. Furthermore, the smaller "footprint" of the lightweight rigs utilized for microhole drilling and the accompanying reduced drilling waste disposal volumes offer the bonus of added environmental benefits. DOE analysis shows that microhole technology has the potential to cut exploratory drilling costs by at least a third and to slash development drilling costs in half. 


\section{Table of Contents}

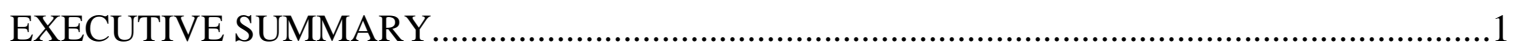



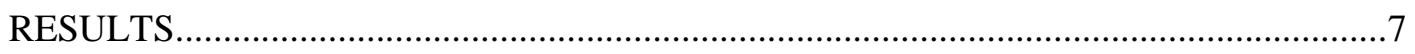

Turbodrill Redesign for High Efficiency.................................................................

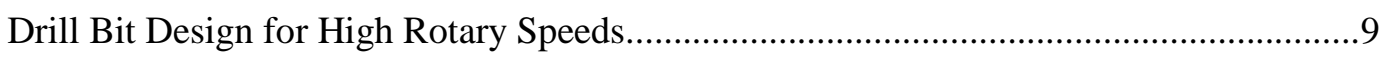

Catoosa Field Test..........................................................27

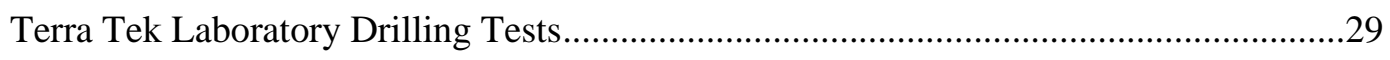

INSTRUMENTATION, CONTROLS, AND DATA ACQUISITION ...............................30

Test Parameters.......................................................................................................

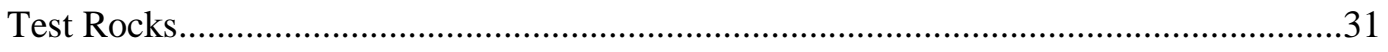

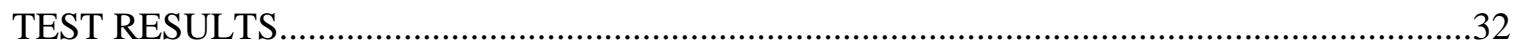

Test 1- NASA Blade Turbodrill Drilling White Sierra Granite with an

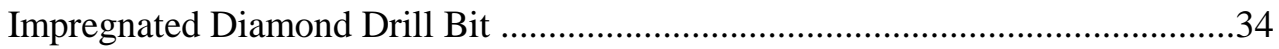

Test 2- NASA Blade Turbodrill Drilling Sandstone with an

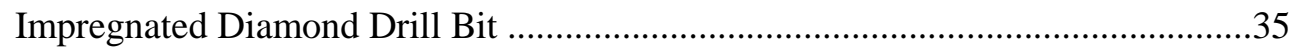

Test 3- NASA Blade Turbodrill Drilling White Sierra Granite with a PDC Drill Bit .....36

Test 4- NASA Blade Turbodrill Drilling Sandstone with a PDC Drill Bit .......................37

Test 5- HEAT Blade Turbodrill Drilling Granite with an

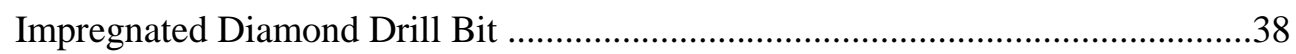

Test 6- HEAT Blade Turbodrill Drilling Sandstone with an Impregnated Diamond

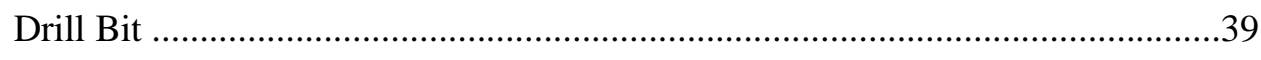

Test 7 and 8 - Heat Turbodrill Drilling Granite and Sandstone with a PDC Drill Bit.....40

Test 9 and 10 - The Commercial Turbodrill Drilling Granite and Sandstone with an Impregnated Diamond Drill Bit........................................................40

Test 11 Commercial Mk2 Blade Turbodrill Drilling granite with a PDC Drill Bit .........40

Test 12 Commercial Blade Turbodrill Drilling sandstone with a PDC Drill Bit............. 42

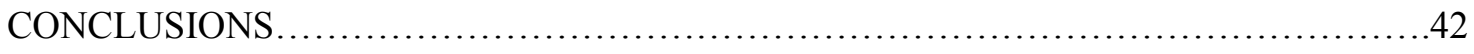

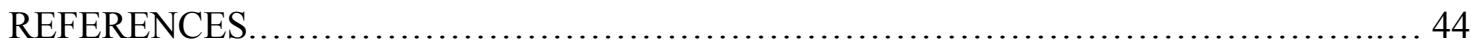




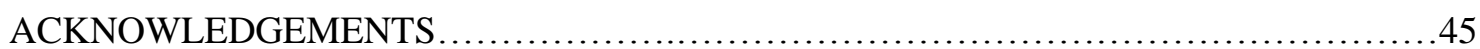

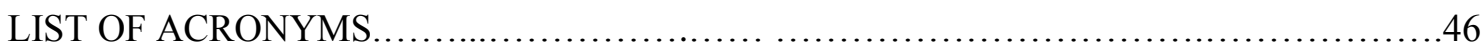




\section{List of Figures}

Figure 1: Direct Drive Turbodrill Components........................................................................... 5



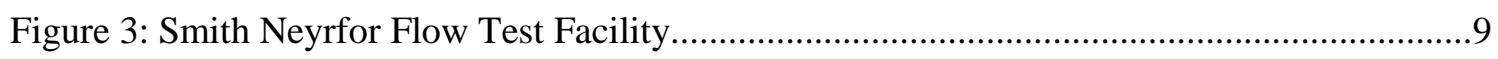

Figure 4: Effect of Weight-on-bit to Achieve Constant ROP as the Cutters Wear .......................12

Figure 5: Cutter wearflat-area distributions at $100 \mathrm{RPM}, 30 \mathrm{ft} / \mathrm{hr}$...........................................13

Figure 6: Cutter wearflat-area distributions at 2,200 RPM ..................................................13

Figure 7: Maximum cutter wearflat temperatures at both rotary speeds......................................14

Figure 8: Cutter 14 Wearflat Temperature at 2,200 RPM ........................................................15

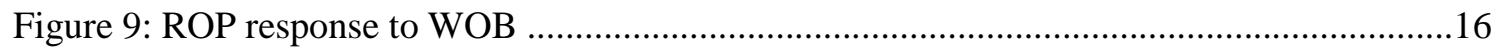



Figure 11: Bit Imbalance-force Ratio (Bit Side Force/WOB................................................... 17

Figure 12: Cutting profiles for drill bit at 100 RPM .............................................................18



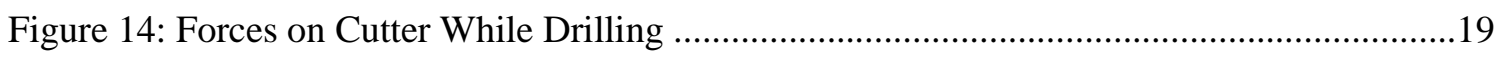

Figure 15: PDC Cutter Wear Rate vs. Temperature ...............................................................19



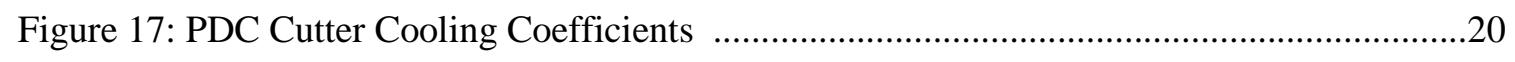

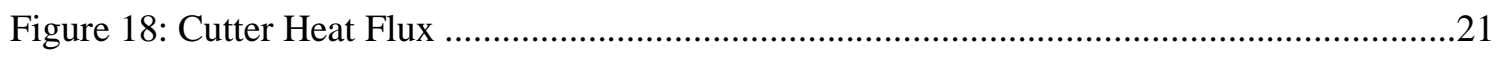



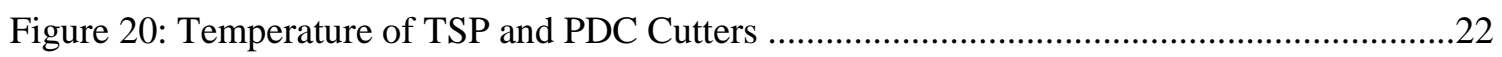

Figure 21: Effect of Rock-Chip Build-up on Temperature ......................................................22

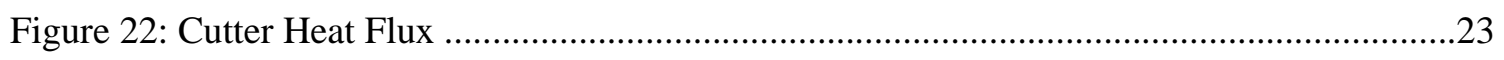



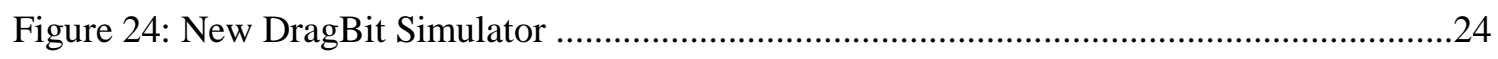

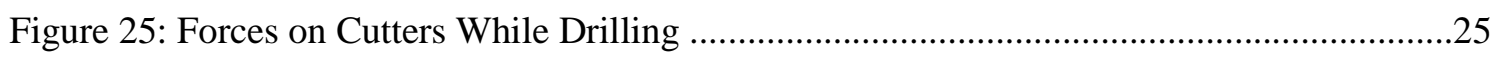

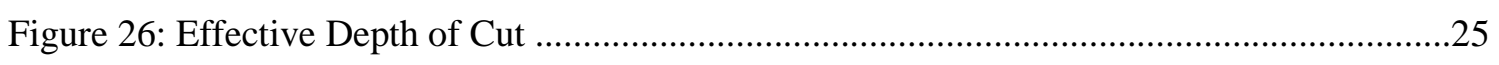

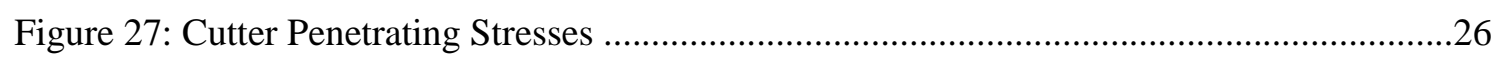

Figure 28: The Turbodrills for the Catoosa I Test ....................................................................27

Figure 29: Fixed Cutter 4-1/8” Bit for Coiled Tubing Drilling ..............................................2

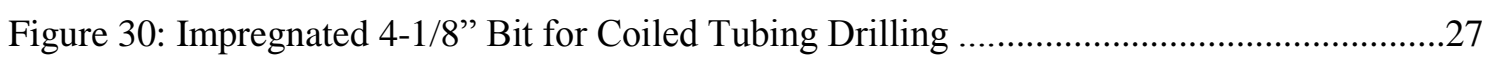

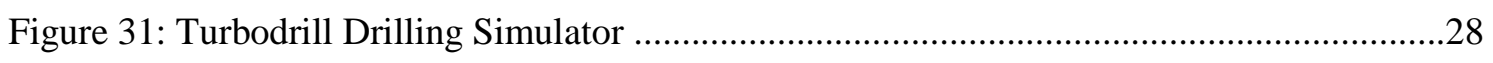

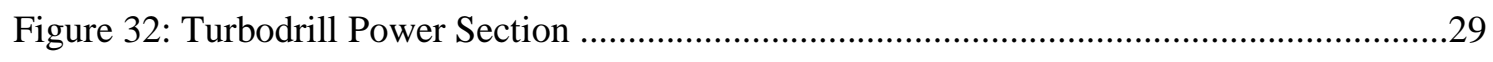








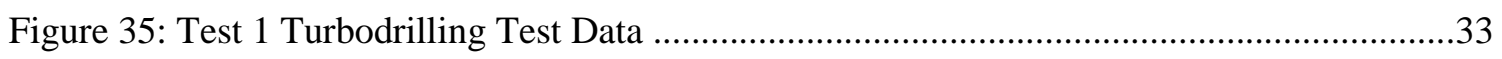





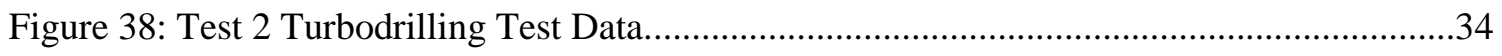

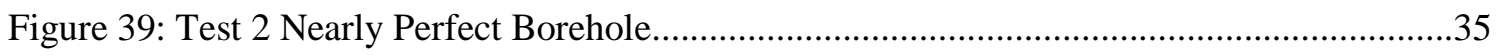

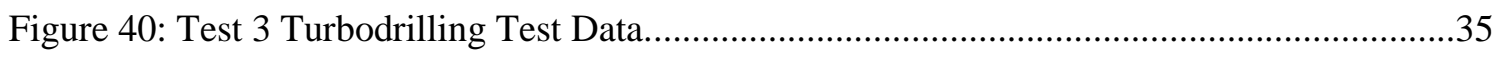

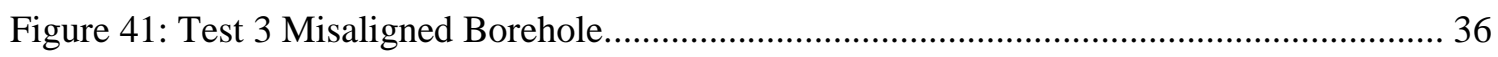

Figure 42: Test 4 Turbodrilling Test Data............................................................................



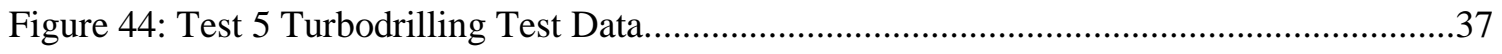

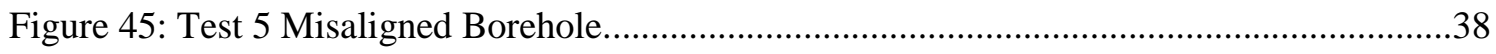



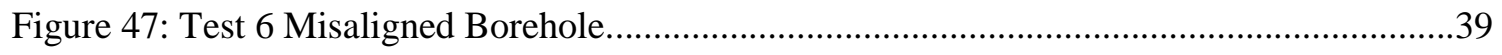

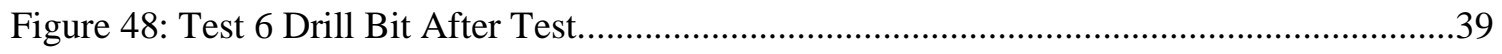

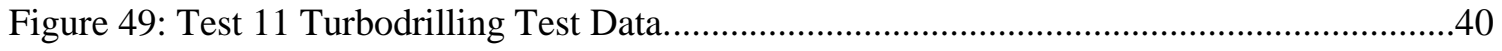

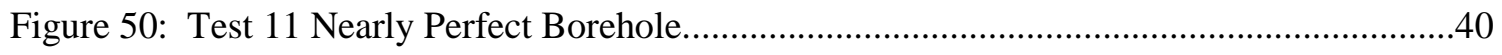

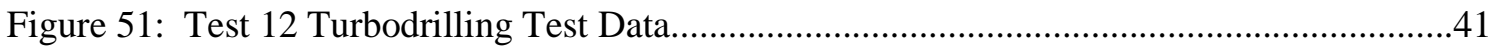




\section{List of Tables}

Table 1: Test matrix showing the turbine, bit, rock, and flow and WOB used for each test...........30

Table 2: Test Rock Physical Properties...................................................................................... 31

Table 3: Planned Test Operating Parameters................................................................................33 


\section{Executive Summary}

The project goal entailed developing and testing an effective downhole drive mechanism and a novel drill bit for drilling small-diameter vertical and horizontal wellbores with coiled tubing. The work was performed by Technology International, Inc. (TII) as the prime contractor, with major contributions by NASA AMES Research Center, Smith Neyrfor and Smith Bits, Houston, TX, (now a Schlumberger Company), the Gas Technology Institute (GTI), Field Test Site, Catoosa, OK, and Schlumberger Terra Tek Drilling Laboratory, Salt Lake City, UT. The initial effort was the baseline testing of an existing 2$7 / 8$ in. diameter Turbodrill with a 4-1/8 in. diameter polycrystalline diamond compact (PDC) and thermally stable (TSP) cutters, and an impregnated diamond drill bit at GTI's Catoosa, OK field test site.

The project plan was to establish baseline performance of the commercial Smith Mk2 Turbodrill at the GRI Field Test Site, the design and manufacture and test of two prototype Turbodrills and two high speed drill bits.

- Phase \#1: Design

- Catoosa Field Test of in. Turbodrill - Baseline

- Higher Power Turbodrill Blade

- Turbine Blade (Computational Fluid Dynamics) - Smith Neyrfor

- Turbine Blade (Response Surface Methodology) - NASA-AMES team

- Drill Bit Design

- Finite Element Thermal Modeling

- High Temperature Cutter Fabrication

- Phase \#2: Manufacturing Prototypes

(Turbodrills and High Temperature Drill Bits)

- Phase \#3: Prototype Testing

(Terra Tek Drilling Laboratory)

To facilitate the design and testing of a more efficient turbine blade design. NASA AMES Laboratory in Palo Alto, CA, (NASA) was contracted to increase the hydraulic efficiency of the existing Smith Neyrfor baseline SII MK2 turbine blades using proprietary design software and techniques. The "NASA" blade design ultimately improved efficiency by approximately 13 percent and power by $29 \%$. Basic research performed at NASA in evolutionary algorithms, response surface methodology, and geometry modelling and the associated codes was utilized to improve the hydraulic efficiency of the Turbodrill. Flow tests run by Smith Neyrfor indicated that the improved efficiency of the NASA designed blades and actual efficiency values were determined during tests at the Terra Tek Drilling Laboratory.

Testing at Terra Tek included the evaluation of the two Turbodrills with prototype blades, commercial Turbodrill for baseline comparison, and two drill bit designs. The two drill bits used in this testing were $4-1 / 8$ " in diameter and included a diamond impregnated bit, and a fixed cutter polycrystalline diamond compact (PDC) bit augmented with thermally stable (TSP) cutters.

Two prototype 2-7/8 in. Turbodrills were manufactured Smith Neyrfor, one with a new Heat ${ }^{\mathrm{TM}}$ turbine blade design and the second with NASA designed turbine blades. Both were considered improved blade designs for increased efficiency. The first were designed by Smith Neyrfor using conventional physical hydraulic models, and the second was the one designed by NASA AMES. Each blade type was incorporated into a 2-7/8 in. Turbodrill and flow tested at the Smith Neyrfor test facility in Houston. The free-wheeling blade speeds were as much as 4,000 RPM. 
The advanced PDC drill bit employs unique TII microwave-brazed TSP cutters. Use of the cutters allows the bit to be rotated at higher speeds than conventional rotary speeds without the excessive wear that would occur if commercially available PDC cutters were used.

A thermal model, based on work previously performed at the Sandia National Laboratory, was revised by TII to predict cutter temperatures while drilling hard and abrasive rock at high rpm. Being able to estimate cutter tip temperatures has aided in the development of a more durable drill bit employing hightemperature cutters. Finite-element thermal modelling (FE) of TSP cutters were produced by DragBit, a Windows-based program that calculates both PDC and TSP cutter forces, cutter temperatures, cutter wear rates, weight-on-bit, drilling torque, and bit imbalance forces for a given bit design, based on downhole operating parameters such as rock type, fluid temperature, fluid cooling rate, rotary speed, and penetration rate. Based on cutter wear rates, the cutter geometries are modified throughout the simulated drilling process to calculate the effects of cutter wear on bit performance. The software allows both TSP and PDC cutters to be specified on the same bit, thereby allowing the user to optimize the placement of TSP cutters in the higher-temperature positions across the bit face. Cutter temperatures and wear rates as well as overall bit performance parameters were estimated for rotary speeds up to 2,200 RPM in order to simulate drilling with the improved Turbodrill.

Thermal modelling of the TSP cutters revealed an unexpected result: TSP cutters appear to be able to be rotated at speeds of at least 2,000 rpm without excessive wear. Because of their high thermal conductivity, the TSP cutters stays cooler, and thus will operate with less wear compared with even the new so called "leached" PDC cutter.

The prototype coiled tubing Turbodrill and drill bit developed in this project were designed to drill a vertical hole to a depth of 5,000 feet, laterals to 1,000 feet., and demonstrate the economic advantages of the coiled tubing drilling operation when compared with conventional drill pipe-conveyed downhole assemblies. Benefits to the industry from successful development of a microhole coiled tubing Turbodrill and high-speed drill bit include:

- Delivery of more power to the bit than with previously available 2-7/8 in. Turbodrills or positive displacement motors (PDM's).

- Lower reactive torque for improved directional control.

- Longer drill bit life

- Less vibration

- Steady dynamics at the bit

- Smaller cuttings are easier to clean from the hole

- Drilling at a higher rate of penetration (ROP) with less weight on bit (higher rotary speeds to 3,000 rpm provide

- Higher ROP and lower cost per foot drilled)

- Operation at high downhole temperatures

- Operation in two-phase muds at higher rotary speeds and for underbalanced drilling applications

- Improved hole quality

- High reliability 


\section{Introduction}

Dr. Steve Holditch, 2002 president of the Society of Petroleum Engineering said "To economically recover gas we need to learn how to drill smaller boreholes more rapidly and less expensively." The American Petroleum Institute publication, Coiled Tubing Drilling: "A Novel Alternative to Conventional Drill Rigs" states that lower cost drilling techniques are needed to economically drill shallow gas and oil wells needed to reach the reserves of oil and natural gas to get to work and school, harvest our food and run our businesses, appliances, computers and factories. But drilling today does not necessarily mean using a conventional rotary drilling rig. Coiled tubing units are being increasingly used to drill for oil and natural gas deposits for less cost and with a much smaller environmental footprint. With conventional drilling rigs, hundreds of 30 foot sections of rigid drill pipe are continuously threaded together to reach deep below the surface. Large crews are required to thread the pipe together after each 30 feet of hole is drilled. To ensure that sufficient weight is put on the drill bit to destroy the rock formations, heavy weight drill collars are placed in the drilling assembly below the drill pipe. To drill, the entire string of pipe is spun rapidly so that the bit on the end of the drill pipe can penetrate the rock formations. This requires lots of power and a large derrick to hoist the drill pipe up so that it can be threaded together. Each time that the bit becomes dull, the entire string of pipe has to be pulled up and unthreaded a joint at a time to remove the bit from the hole.

A cost-effective alternative, especially for drilling highly deviated wells or drilling new hole sections in existing wells is coiled tubing drilling. Coiled tubing units consist of a continuous length of flexible pipe that is coiled onto a spool, much in the way that cable is spooled. Thus, crews are not needed to thread the pipe together and large derricks are not needed to hoist the pipe in the air for threading and unthreading. Instead of rotating the entire string of drill pipe to turn the bit, the bit is turned by pumping mud through a turbine motor, known as a Turbodrill which spins only the bit. Mud is used in all drilling operations to cool the bit, remove rock pieces from the hole, contain formation pressures and keep the hole from collapsing. The benefits of using coiled tubing units for drilling include:

- The units require about half the surface area that a conventional drilling rig requires. The units require less power so there is less fuel consumption and emissions during drilling. Noise levels are 18 percent lower than with conventional rigs.

- There is less visual impact as the units are small with no large derrick tower.

- The units require fewer workers and have less rotating equipment, so they are generally safer to operate.

- Smaller volumes of drilling mud are needed, and a smaller volume of rock cuttings is created during drilling because the drilled holes are a smaller diameter.

- Set-up time is greatly reduced. Drilling time is also reduced because the drill pipe does not need to be threaded and unthreaded. Changing dull bits is also quicker because the pipe is just rolled back on the spool to pull the bit out of the hole.

- Coiled tubing units, because they are smaller and lighter than conventional drilling rigs, are more easily transported by truck, barge, ship or helicopter.

All of this means that coiled tubing units are more cost-effective, energy-efficient, have a much smaller footprint, and create less waste. In certain drilling operations, coiled tubing units cost approximately half of what a conventional drill rig would cost. The successful commercial introduction of Microhole Technology (MT) to the gas and oil drilling industry requires an effective downhole drive mechanism for delivering power to the drill bit, such that run hours and rates of penetration result in cost-effective drilling performance. 
Applications for Coil Tubing Downhole Motors include drilling, production remediation, and shallow seismic exploration holes for burying arrays, and Vertical Seismic Profiling (VSP) during the drilling operation. Initial tests of prototype hardware was conducted at drilling research centers to expedite the testing process and to ensure maintenance of carefully controlled operating conditions not compromised by customers' operational drilling requirements. However, because of Smith Neyrfor's position as the leading provider of Turbodrilling services in the oilfield, much of the subsequent testing was accomplished in wells drilled with conventional drill pipe and in workover applications using conventional coiled tubing rigs for operations such as scale removal. This approach served to both reduce development time and minimize total costs necessary to meet project objectives.

The use of turbine motors ((i.e. Turbodrills) is over a hundred years old and was first applied to oilfield drilling in the USSR in 1924. Neyrfor introduced the first steerable downhole drilling motor in 1982. Neyrfor was purchased by Smith International. Advanced PDC bearings were introduced into Turbodrills in 1992. Bent housing Turbodrills were also introduced in 1992. Speed reduction gearing for Turbodrills was introduced in 2001.

A Turbodrill power section is entirely metallic (metallic turbine blades, metallic shaft, metallic housing, etc.), therefore, the tool is extremely resistant to high temperatures and high pressures. Historically, Turbodrills have proven to be the most reliable drive mechanism in elevated temperature environments. In many cases, Turbodrills are the exclusive drive mechanism used in high temperature/high pressure areas because of the tool's ability to reliably operate in extreme environments.

Many critical developments have contributed to the growing success of Turbodrills and high speed drill bits. The term 'high speed drill bits' (HS bits) is meant to describe any type of drill bit that is compatible with high speed Turbodrills which, depending on tool size, will produce an output speed from 700 to about 2,000 RPM. Most of the developments associated with this system have been focused on improving the durability and reliability of the system. Because Turbodrills and HS bits are both made from very expensive, tight tolerance components, there must be a significant performance benefit when using the system to justify the increased cost of the system. That benefit can be realized in the form of improved ROP, improved run length, reduced trips, improved hole quality, improved directional performance, improved hole cleaning, or a variety of other factors. However, in most cases, it is easiest to justify the expense of the system through either an increase in ROP or a reduction in the number of required trips. Therefore, the durability and reliability of the Turbodrill/HS bit system is of primary importance

Some of the most important developments concerning the durability and reliability of this drilling system are found in Turbodrill bearings. The bearings, both radial and thrust, maintain the appropriate turbine blade position, radially and axially, allowing them to perform as designed. Since Turbodrills are very long lasting tools that run in high RPM ranges, the development of bearing technology has been crucial to the durability of the tool. One of the most important developments in bearing technology has been the optimization of PDC thrust bearings. Bearings, through diamond to diamond contact, support the axial thrust and rotations created by the turbine blades and reside in the bearing section (Figure 1). 


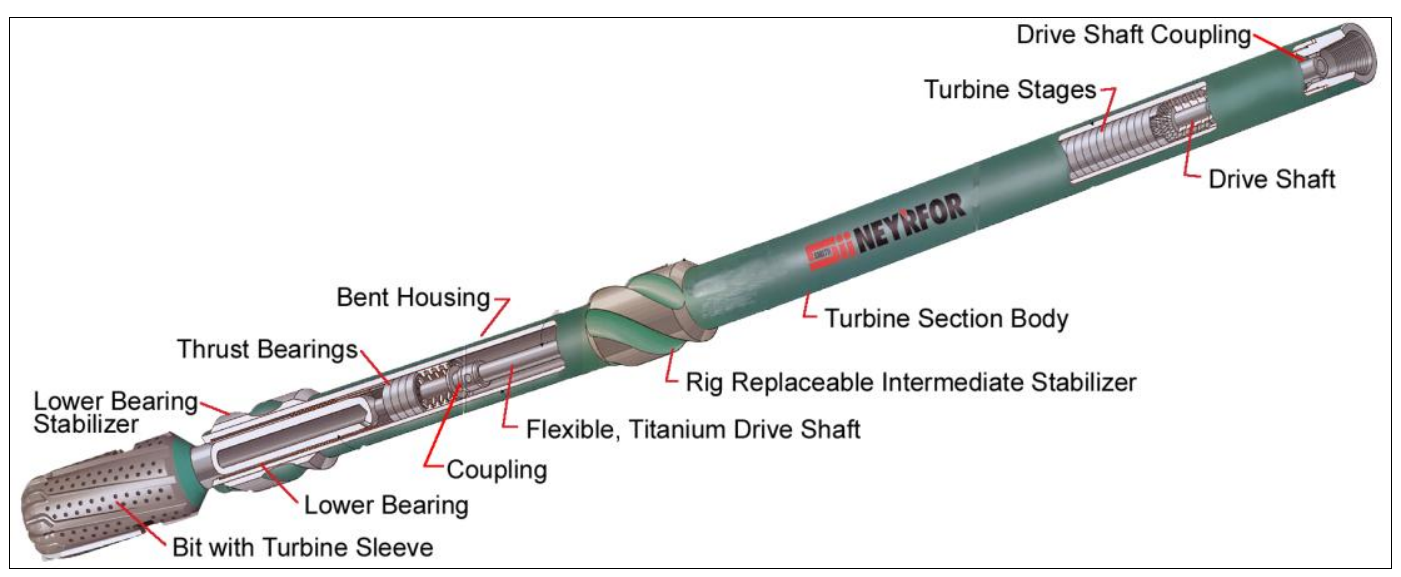

Figure 1: Direct Drive Turbodrill and Components

This diamond to diamond contact, between the rotor and stator components of PDC bearings, provides the ultimate resistance to compression loads, rotational abrasion, and high temperatures. PDC bearings have many advantages, but the most important of these are a very low coefficient of friction and a very long life in demanding applications. Diamond-to-diamond interfaces, particularly when lubricated by the drilling mud, produce very little friction, thereby absorbing axial thrust with very little energy lost in the process, contributing to overall higher tool efficiency.

Along with the development of PDC thrust bearings, several innovative technologies have improved the wear resistance of Turbodrill radial bearings. These technologies have fundamentally focused on the development of more abrasion resistant materials and coatings, but Turbodrill designs are also a function of the development of exacting dimensional tolerances. A unique characteristic of the Turbodrill is that the entire tool runs concentrically, with very small radial bearing clearances. Since the tool is designed to be concentric, with very tight tolerances on many parts to maintain balance, loads on the radial bearings are manageable, and corresponding vibration levels are quite low. It is therefore possible to focus the engineering effort of radial bearing development on the abrasion resistance of the bearing surfaces in order to manage bearing wear, even at high RPM and on very long runs.

Another development critical to the durability of the Turbodrill/HS bit system is the improved durability of impregnated bits (diamond impregnated drill bits). Turbodrills are generally used either with PDC drill bits or impregnated drill bits. The development of this system has basically excluded rock bits, due to their obvious limitations at high speeds and relatively short drilling life in extreme environments. Although there are many applications well suited to the use of PDC drill bits and Turbodrills, those applications do not tend to be applications where durability is the limiting performance factor. When PDC bits are used with Turbodrills, it is normally for the enhanced ROP of that system, in comparison to the impregnated bit/Turbodrill system, and therefore, durability is not the primary driver for performance development. In contrast, the Turbodrill/impregnated bit system is often used in applications where durability is the most important factor. In these applications, the ROP tends to be low, due to high compressive strength rock and deeper drilling intervals. Therefore, a critical factor in improving overall performance is staying in the hole for as long as possible, to reduce, or eliminate, the costs associated with making long bit trips. In the recent past, impregnated bits have made great strides in improved durability for these applications. These improvements have been a combination of material science advancements coupled with bit design improvements. With the development of very durable impregnated bits, and the utilization of the very reliable Turbodrill, it has become possible to drill long intervals in very difficult formations, thus reducing trip time and the overall drilling time. 
In the drilling environment, the easiest performance measure is the ROP. For fixed cutter bits, whether a PDC drill bit or impregnated bit, there is a ROP limit attributed with the design of the bit. With an impregnated bit, the rock is failed through a grinding operation using small natural or synthetic diamonds as the cutting structure. The diamonds used in these bits have a very low maximum depth of cut (DOC). Consequently, the most effective method for increasing the ROP for this type of cutting structure is to increase the RPM. Since each revolution of the bit can only penetrate the rock by a small distance, the more frequent the revolutions, the faster the overall ROP. As mentioned above, in the design of impregnated bits over the last few decades, the majority of the development effort has centered on increasing the durability of the bit. This is due to the fact that most of the formations that are commonly drilled by impregnated bits are very hard, hard and abrasive, or very abrasive. It has also been proven that not only higher speeds, but higher power supplied to the bit, will also improve performance in most instances. However, as indicated above, since the DOC of an impregnated is relatively low, the maximum attainable ROP of the bit is also relatively low, regardless of the power or weight on bit (WOB) applied to the bit.

In general, current impregnated diamond drill bit designs are very durable, but often fall behind in ROP potential when compared to PDC or roller cone bits. This can be understood by evaluating how each type of cutter fails the rock. Research and development efforts are underway to develop impregnated designs that will increase the ROP through cutting structure aggressiveness and hydraulic efficiency, without compromising the durability that is so important to overall performance.

In comparison, PDC bits often achieve good ROP, due to the shearing action by which the rock is failed. Theoretically, this cutting action can provide a much better penetration rate than the grinding action of an impregnated bit. However, in harder and/or more abrasive formations, when running at high RPM, the durability of PDC cutting structures is currently relatively limited, especially when compared to impregnated bits. That is not to say that there are not applications for running high speed Turbodrills with PDC bits, there are many such applications. However, the applications that are currently suitable for the HS Turbodrill/PDC drill bit system tend to be in applications that are either not both hard and abrasive, or not highly abrasive, regardless of formation strength. Many developments are underway both in PDC cutting structure design and PDC cutter technology to address the excessive wear issue and allow PDC drill bit designs to add durability to a good record of ROP. The development of the geared Turbodrill has also had a beneficial impact on the suitability of PDC drill bits because geared Turbodrills operate at lower RPM than direct drive Turbodrill.

Many different approaches are currently under investigation to improve the performance of the Turbodrill/HS drill bit system. Research and development is proceeding on PDC and impregnated bits in combination with Turbodrill configurations to maximize the system potential. These efforts include increasing the ROP potential of impregnated bits, increasing the durability of PDC bits, and optimizing the power delivery of the Turbodrill at the various operating parameters.

PDC bits often achieve good ROP, due to the shearing action by which the rock is failed. However, when run with Turbodrills in hard and/or abrasive drilling environments, they often wear quite rapidly. Many developments are underway both in PDC cutting structure design and PDC and thermally stable diamond cutter technologies to address the excessive wear issue and allow PDC drill bit designs to add durability to a good record of ROP.

The purpose of the proposed project is to protect the environment, reduce the cost and increase the safety of drilling 5,000 feet onshore petroleum wells with 1,000 feet laterals. This proposed project delivered a downhole, hydraulically-driven power unit, matched with a custom drill bit design, with the power unit/drill bit system designed specifically to provide an optimized combination of run life and penetration 
rate when used to drill 4-1/8" boreholes meet these depth and horizontal requirements, with a purposebuilt coiled tubing rig. The goal is an advanced Turbodrill and Drill Bit systems.

Major objectives were to (a) establish a baseline performance by initially drilling with commercially available 2-7/8 in. Turbodrills and coil tubing bits, (b) increase the performance of turbine and drill bit components, (c) model the turbine and drilling process to achieve drill bit performance that will deliver the optimum performance affordable with the Turbodrill-bit combination, (d) manufacture the prototype Turbodrill and optimized drill bit and demonstrate the improvements in ROP and equipment life while drilling at the GTI Catoosa field test site, and the Terra Tek Drilling Laboratory.

\section{Results}

Initially, a design review was held in Tulsa, OK with the DOE technical staff. The agenda included (1) Catoosa field test benchmark drilling record with the commercial 2-7/8 in. Smith Neyrfor Turbodrill and Smith Bits drill bit performance, (2) FE thermal and Neural Network based aerodynamic vane modelling results, (3) the redesign of the in. Smith Neyrfor Turbodrill, and (4) a coil tubing drill bit redesign.

A commercial 2-7/8 in. Smith Neyrfor Turbodrill with an "aggressive" Smith Bit drill bit with polycrystalline diamond cutters (PDC) and thermally stable diamond (TSP) cutters was field tested at the Gas Technology Institute (GTI) field test site at Catoosa, OK to establish benchmark performance. A commercial Turbodrill and drill bit hardware for drilling 4-1/8 in diameter hole using existing Turbodrilling and drill bit technology was used to establish "benchmark" performance at the GTI Catoosa Test Site using jointed drill pipe and a downhole assembly to simulate coiled tubing drilling. The downhole assembly included a commercial Smith Neyrfor 2-7/8 in. directional Turbodrill and an "aggressive" Smith 4-1/8 in fixed cutter drill bit specifically designed with to include thermally stable diamond cutters. The motor section for the Smith MK2 Turbodrill is designed to rotate at 1,100 to 2,000 RPM depending on mud weight, pressure drop, and flow rate. The drill test was designed to establish a baseline for the manufacture of prototype Turbodrill and high speed drill bit. The detailed results of the Catoosa testing are reported herein. Improvements were incorporated into a prototype Turbodrill and drill bit that was tested at the Terra Tek Drilling Laboratory. The prototype Turbodrills, HEAT and NASA

\section{Turbodrill Redesign for High Efficiency}

Turbodrills obtain hydraulic power to rotate a drill bit from the flow of drilling fluids, (mud, foam, or air). This hydraulic flow is converted to rotary movement by a system of blades within the turbine assembly. They may be variable pressure profile blades or constant pressure drop blades. The efficiency of the turbine section rotor and stator blade is the effectiveness to convert hydraulic energy to mechanical energy in the form of rotation and torque at the bit. The Smith Neyrfor commercial Turbodrill efficiency is 50\%. TII contracted NASA Ames Research Center to apply for the first time to petroleum downhole Turbodrills, new turbine design software based on an aerodynamic design optimization procedure using neural networks and "response surface methodology" (RSM). New blade and stator profiles were successfully designed and tested.

Dr. Man Mohan Rai at the NASA Ames Research Center, Moffett Field, CA has developed a series of fluid dynamic algorithms and neural networks which have been successfully used for redesign of turbine blades to optimum efficiency. Dr. Rai produced an improved blade design given the mechanical operating requirements and hydraulic flow conditions, both steady and unsteady flow. Additionally, since flow conditions change, it is possible to maintain near-optimal performance levels at otherwise off-design operating conditions. Additionally, the accuracy to which the optimal shape is manufactured depends on 
the manufacturing tolerances and normal wear and tear. These requirements lead to the need for a robust optimal design solution. Thus, evolutionary algorithms are needed, and the learning of the neural network is used to achieve robust optimal design solutions. Both traditional response surface methodology (RMS) and neural networks are incorporated in this design method by a strategy called parameter-based partitioning of the design space. Starting with the reference design, a sequence of turbine vane response surfaces based on both neural networks and polynomial fits are constructed to traverse the turbine vane profile in search of the optimal solution. Figure 2 shown below is an illustration of computational fluid dynamics as it applies to the Turbodrill. To our knowledge, this was the first use of these state-of-the-art techniques for petroleum Turbodrills. Dr. Rai presented the results of his modelling and methodology while training Smith Neyrfor project personnel in the use of the system.
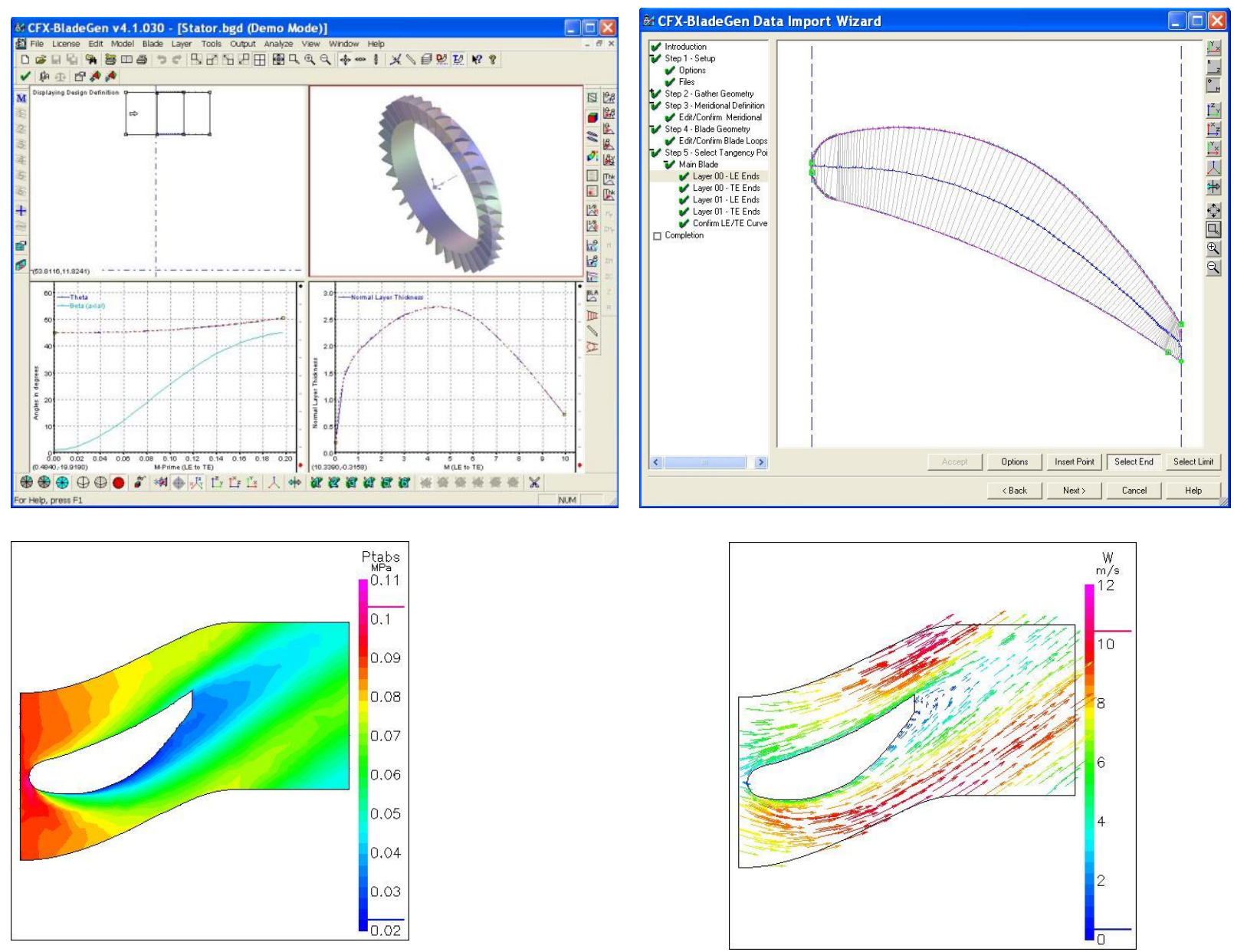

Figure 2: Computational Fluid Dynamics

Changes to the turbine blade profiles gave $13 \%$ more power per stage, reducing the required number of stages and further reducing assembly length. Further, the power was increased by $29 \%$. Conventional, constant pressure drop, turbine blades produce very similar pressure drops, whether the tool is off bottom with the blades rotating at maximum RPM or stalled out on bottom with no blade rotation. The new blade profile reduced the pressure drop through the blades as RPM decreases.

Elastomer thrust bearings are used for low temperature and high mud weight applications, while tungsten carbide radial bearings for high temperature wells, and PDC thrust bearings are used for high temperature 
and high mud weight applications. The PDC thrust bearings used on the in. conventional Turbodrill bearings were tested to review bearing design adequacy for the coiled tubing drilling application, even though the rated design life exceeds 200 hours.

Flow tests and runaway rotary speed data was obtained using the Smith Neyrfor test facility shown in Figure 3. An optical tachometer was used to measure speeds from 2000 to 4000 RPM.

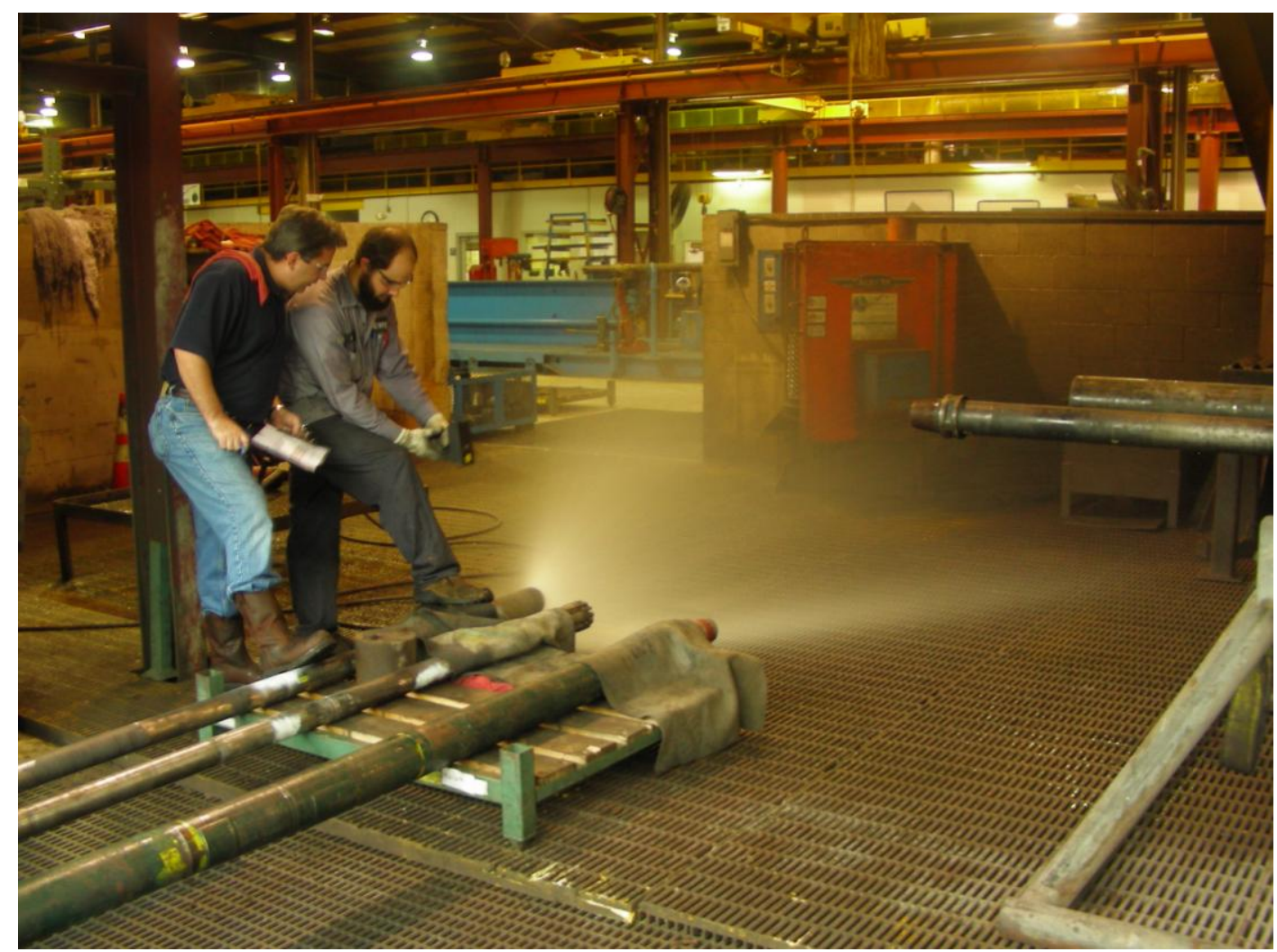

Figure 3: Smith Neyrfor Flow Test Facility

\section{Drill Bit Design for High Rotary Speeds}

The use of the in. Smith Neyrfor at high rotary speeds of 2000 to 4000 RPM means that the traditional PDC may experience excessive wear and that a thermally stable cutter is desirable for economical drilling. The bit designer has many software tools to predict the design of a force balanced bit and predicted ROP. A model was developed to predict the cutter temperature while drilling. Even soft formations when drilled with conventional rotary speed at very high ROP, 300 feet per hour, cause excessive PDC cutter wear do to heat. A finite element model (FE) is needed so that the designer can select either a PDC when the cutters are less than $300^{\circ} \mathrm{C}$, or the TSP cutter when higher temperatures are expected. The thermally stable cutter wear rate does not change with temperature to/at $1,000{ }^{\circ} \mathrm{C}$, while the PDC wear rate is exponential with temperature above $300^{\circ} \mathrm{C}$.

First, the thermal response of a TSP bit and its subsequent performance and wear is to develop a thermal numerical model of a single cutter. This was accomplished with commercial software on a PC/Windows platform, as an extension to work performed by Sandia National Laboratories for PDC cutters. 
Three-dimensional models were developed for various wear conditions, ranging from sharp to severely worn. Two dimensional models were used in previous work at Sandia National Laboratories. Appropriate boundary conditions for such a model include frictional heating at the wearflat, convective cooling along the TSP diamond face and sides of the cutter, and heat conduction into the body of the bit. Appropriate values for all these conditions are known from previous work.

The output from such a model is the temperature field throughout the cutter. Of critical importance here are the temperatures and thermal gradients along the TSP diamond face, at the diamond/cutter interface, and along the cutter wearflat. These predictions allowed the thermal stresses throughout the cutter to be estimated. In addition the mean temperature along the wearflat can be calculated, which leads to a single, quantitative parameter known as the thermal response function. This parameter is basically the mean temperature rise, per unit heat input, of the cutter wearflat above the ambient fluid temperature. It is a function of the convective cooling rate and the cutter wear configuration.

The thermal response function can then be used in a classical analytical solution for a sliding heat source along a semi-infinite slab, in this case the rock surface. This solution provides a partitioning of the frictional heat between the cutter and the rock and is a function of the friction coefficient, the sliding velocity, and the rock's thermal properties. Again, appropriate values for all these parameters are known from previous work.

The result of this task was a model used to predict the mean wearflat and diamond-face temperatures of a TSP cutter under a wide variety of conditions. The ability to predict these temperatures allowed the severity of the frictional heating and the subsequent performance and wear of a single TSP cutter was assessed for the wide range of conditions existing for a TSP cutter on a high-speed motor.

Then, the thermal model of the single TSP cutter was exercised to characterize the range of thermal response expected of a given TSP cutter on a high-speed bit. Parameters such as cutter speed, weight-oncutter, drilling fluid cooling rates, and rock type was varied to predict the cutter wearflat and diamondface temperatures. These results provided valuable insight regarding the thermal effect of variables, some of which can be controlled and some of which cannot be controlled.

For example, the velocity of a cutter at a given location on a bit turning at a specific rotary speed cannot be changed; but the weight on that cutter can be controlled to a certain extent by providing additional cutters at or near that radial location. This is the so-called cutter redundancy that is an important factor in TSP and PDC bit design. Likewise, the thermal properties of a given rock type cannot be controlled; but the cooling rate of a given cutter can be controlled to a large extent with proper hydraulic design of the bit.

The PDCWEAR code developed by Sandia National Laboratories has been extensively used by the PDC bit industry to guide the design and to predict the performance of their bits over the past two decades. The code allows a designer to specify many bit design and operational parameters, such as the location of cutters on the bit face, drilling fluid cooling rates, the bit rotary speed, rock characteristics, and the bit penetration rate, among others.

Based on these inputs, the code predicts the individual cutter loads, temperatures, and wear rates, and it integrates these across the bit face to predict total bit performance parameters such as weight-on-bit, drilling torque, bit side loading, and bending moments. One of the unique features of this code is its ability to determine the interaction of nearby cutters and the effect of this interaction on cutter loads and wear rates. 
As the bit is run in virtual space, the individual cutter geometries are modified according to their predicted wear rates, and the cutter and bit performance parameters are calculated again for the next specified drilling interval. Virtual drilling thus proceeds until the bit is worn out, as indicated by any number of cutter or bit performance thresholds. One such threshold is a cutter reaching its critical wearflat temperature, where thermally accelerated wear occurs. Another threshold is reaching a maximum drilling torque or weight-on bit based on practical drilling limitations.

The predicted performance of a given bit can then be compared with the predicted performance of different bits or the same bit with design modifications. It is thus a relatively straightforward matter of iterating toward an optimized bit design for a given rock type or rotary speed. PDC bit companies have successfully used the code to balance their bits, provide appropriate cutter redundancy, and identify potential design problems, to name a few uses, before actually building and running a physical bit.

Under this task, the PDCWEAR code was modified to accommodate the physical properties of TSP cutters and named DragBit. It was modified as necessary to also run TSP bits on high-speed (up to 4,000 rpm) Turbodrills. The various algorithms used to calculate cutter temperatures, cutter interaction, wear rates, and a variety of other phenomena modelled in the code was examined in detail. These algorithms can be changed, where necessary, to account for any significant differences in cutter geometry, bit design practices, or operating conditions posed by using TSP cutters instead of PDC cutters. Any changes thus identified can be implemented in an incremental, methodical manner in order to assess and document the effects of these changes on the performance of the code.

PDCWEAR has been updated so that it now deals better with bits that have multiple redundant cutters. It took a relatively simple fix to the logic to enable the routine to work when very thin, vertical slices of rock are cut by a multitude of gage cutters. This correlation provides a single equation that includes the wearflat heat flux and the wearflat length. Because of the non-linearity of the numerical results and the resulting correlation equation, the program required a routine that iterates on the cutter temperatures at each step. The routine converges fairly rapidly, within 5-10 iterations, so it does not contribute significantly to the program execution time.

Using the upgraded code, two runs of the 4-1/8 "fixed cutter bit were completed. Both runs simulate drilling in Sierra White Granite with water-based mud cooling. The first run uses a bit rotary speed of $100 \mathrm{RPM}$ and penetration rates of 10-50 ft/hr, with cutter wear calculations based on $30 \mathrm{ft} / \mathrm{hr}$. The second run uses a rotary speed of 2,200 RPM and penetration rates of $50-250 \mathrm{ft} / \mathrm{hr}$, with wear calculations based on $150 \mathrm{ft} / \mathrm{hr}$.

Figure 4 gives an overview of the predicted bit performance over its life at both rotary speeds. Bit life is defined as the footage drilled before the largest cutter wearflat reaches through the bond line on one of the TSP cutters. At $100 \mathrm{RPM}$, the bit drilled $1,186 \mathrm{ft}$ at $30 \mathrm{ft} / \mathrm{hr}$ before cutter 15 wore to that point. At 2,200 RPM, the bit drilled only $413 \mathrm{ft}$ at $150 \mathrm{ft} / \mathrm{hr}$ before Cutter 14 wore through the bond line. 


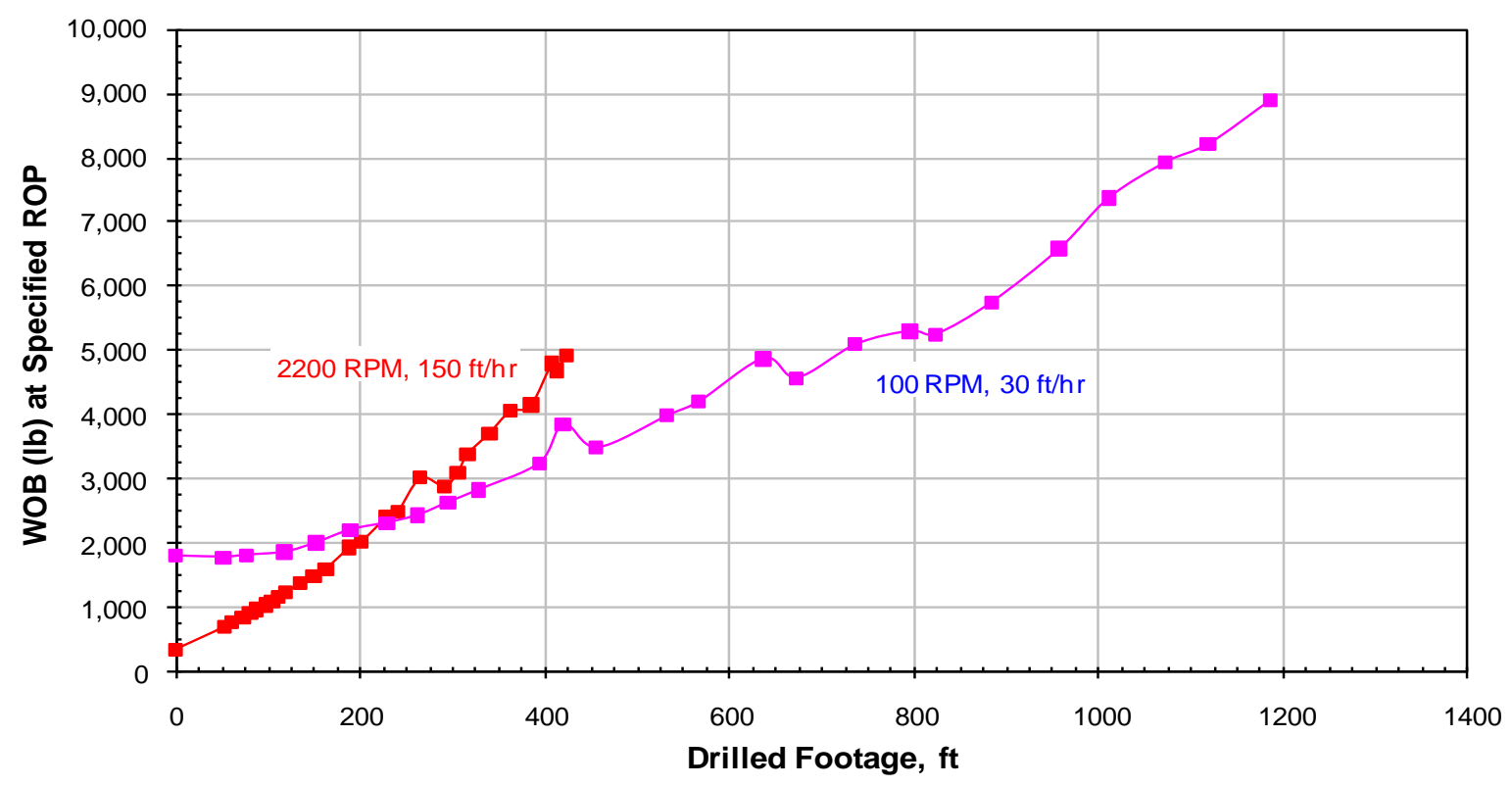

Figure 4: Effect of Weight-on-bit to Achieve Constant ROP as the Cutters Wear

Note that when sharp, the high-speed bit requires only about $20 \%$ as much weight-on-bit to drill 5 times faster than the low-speed bit. To maintain that ROP advantage as the bit wears, however, the high-speed bit eventually requires more WOB at a given drilled footage. This is because the cutters wear faster on a per-foot basis with the high-speed conditions assumed in these runs.

Figures 5 and 6 show the bit wear patterns at three specific points along the way: when the bit is new; when the bit is at the end of its life (the wearflat extends across the TSP bond line on at least one cutter); and when the maximum wearflat area is one-half of that of the "worn-out" cutter.

1) 


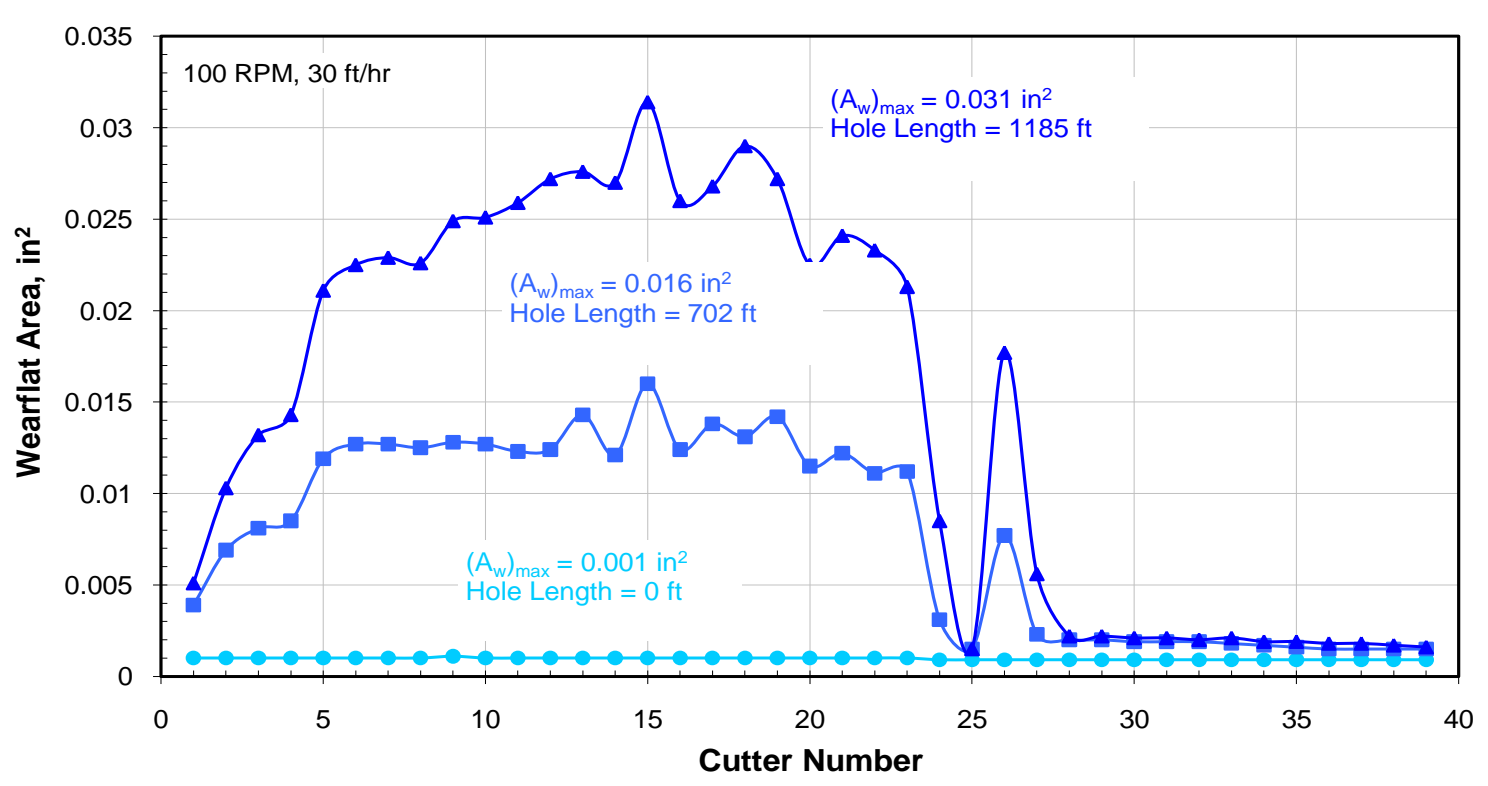

Figure 5: Cutter wearflat-area distributions at $100 \mathrm{RPM}, 30 \mathrm{ft} / \mathrm{hr}$ Note: The largest $\left(0.031 \mathrm{in}^{2}\right)$ wearflat at $1185 \mathrm{ft} / \mathrm{hr}$ reaches across the TSP bond line.

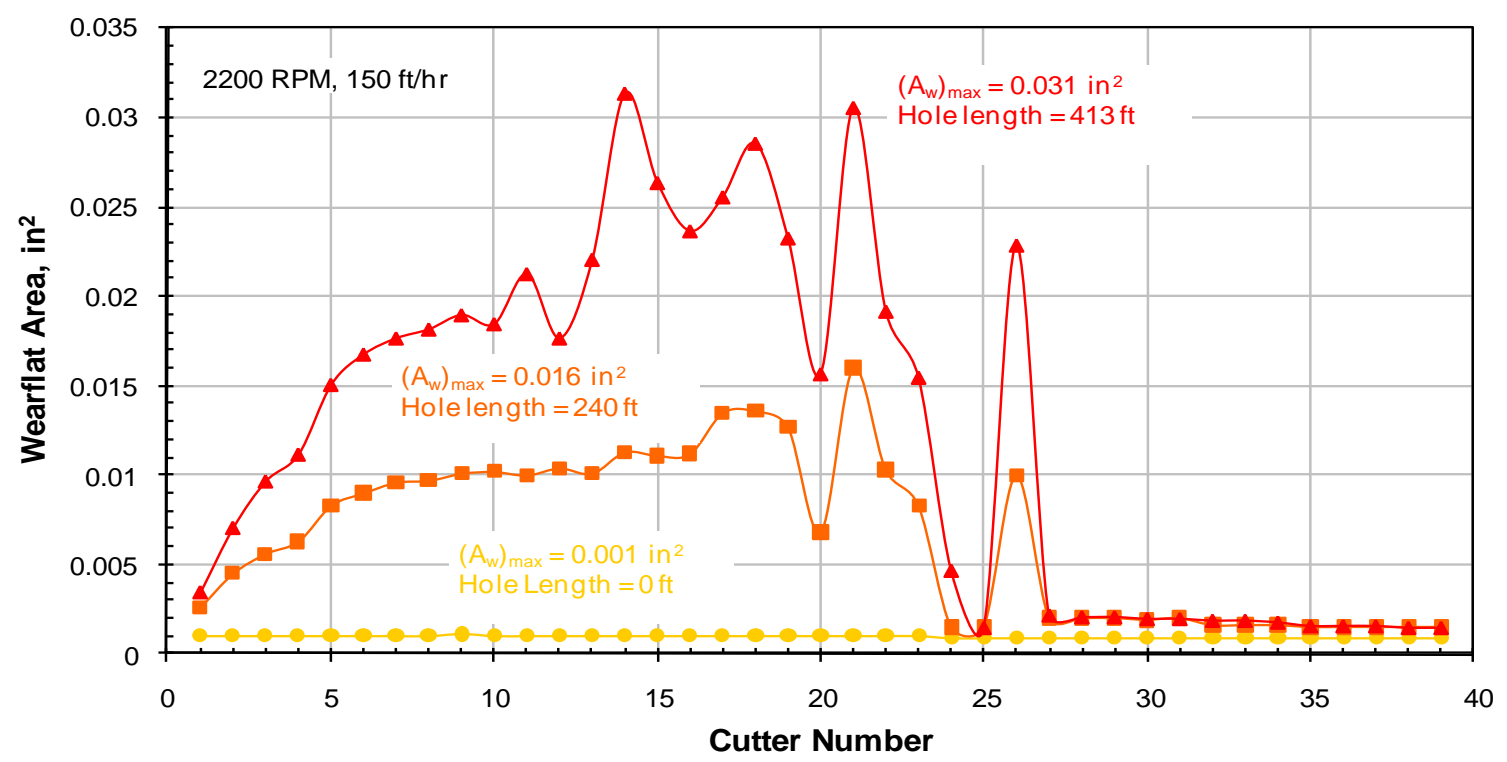

Figure 6: Cutter wearflat-area distributions at 2,200 RPM

Note: The largest $\left(0.031 \mathrm{in}^{2}\right)$ wearflat at $413 \mathrm{ft} / \mathrm{hr}$ reaches across the TSP bond line.

Note that in general, the higher rotary speed shifts the wear to the higher cutter numbers, which are located at larger radial positions on the bit. It can also be seen that there is some room for improving the 
wear pattern of the bit at both speeds because some cutters experience much higher wear than some of the surrounding cutters. Slightly changing the radial and circumferential positions of these cutters could spread the wear more evenly and increase the bit life at both rotary speeds.

The cutter wear model used to calculate these wear patterns assumes the volumetric cutter wear per length of hole drilled to be directly proportional to the cutter penetrating force and radial position on the cutter and inversely proportional to the bit feed rate (inches/revolution). This model does not include any temperature effects, primarily because we had so little quantitative data available in 1986. We knew that wear rates for conventional PDC cutters at that time increased by about an order of magnitude when cutter temperatures exceeded about $350^{\circ} \mathrm{C}$, so PDCWEAR was set up to raise a flag when any cutter temperature exceeds that level. At conventional rotary speeds, that level is usually attained only when one or more cutters become very worn, so the usual interpretation of the flag is as a sign that the bit is worn out. As a practical matter, once thermally accelerated wear begins, there is little additional bit life left anyway.

At the higher rotary speed employed in this study, however, cutter temperatures become significant even when the cutters are still relatively sharp. Figure 7 shows the maximum cutter temperature as a function of drilled footage for both rotary speeds. Results for 2,200 RPM are shown using both the original PDCWEAR thermal model, which was based on numerical modelling employing constant material properties, and the new thermal model for TSP cutters, which is based on temperature-dependent thermal properties. Results for 100 RPM are shown using only the original PDCWEAR thermal model.

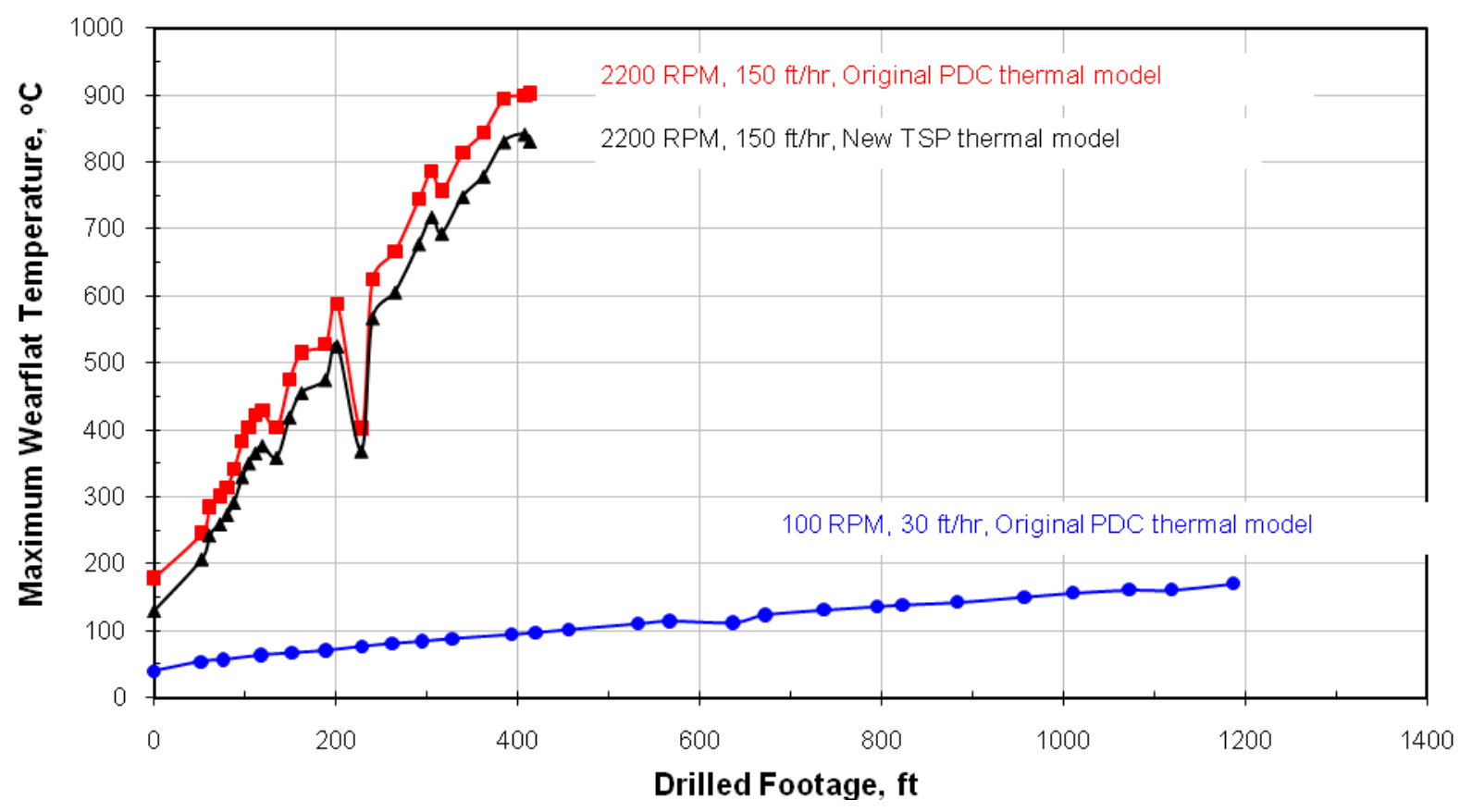

Figure 7: Maximum cutter wearflat temperatures at both rotary speeds

At 100 RPM even with the original thermal model, the cutter temperatures never exceed $170^{\circ} \mathrm{C}$ during the bit's entire life. This is because this bit has so many cutters for its hole size that none of the cutters ever bear a heavy enough load to generate significant temperatures at the low cutting speeds that occur at 100 RPM. 
At 2,200 RPM, however, the maximum cutter temperature exceeds $350^{\circ} \mathrm{C}$ after $104 \mathrm{ft}$ of drilling. It exceeds $600^{\circ} \mathrm{C}$ after about $260 \mathrm{ft}$ of drilling and reaches $830^{\circ} \mathrm{C}$ before the end of the bit's life (at $413 \mathrm{ft}$ based on non-thermal abrasive wear). Note that the new TSP thermal model predicts lower temperatures than the original PDC thermal model. Although the results for the new temperature-dependent PDC numerical modelling have not yet been incorporated into PDCWEAR, those results indicate that the predicted PDC cutter temperatures would be higher than those predicted by the original PDC thermal model. The difference in thermal performance between TSP and PDC cutters, therefore, showed up as very significant when this graph is re-drawn with the updated PDC thermal model predictions.

It should be noted that the cutter with the maximum wearflat temperature changes from time to time as the bit wears, so the data in each curve in Figure 7 are not for a single cutter. The reason for this is illustrated in Figure 8 which shows the cutter temperature for a single cutter (cutter 14) at 2,200 RPM.

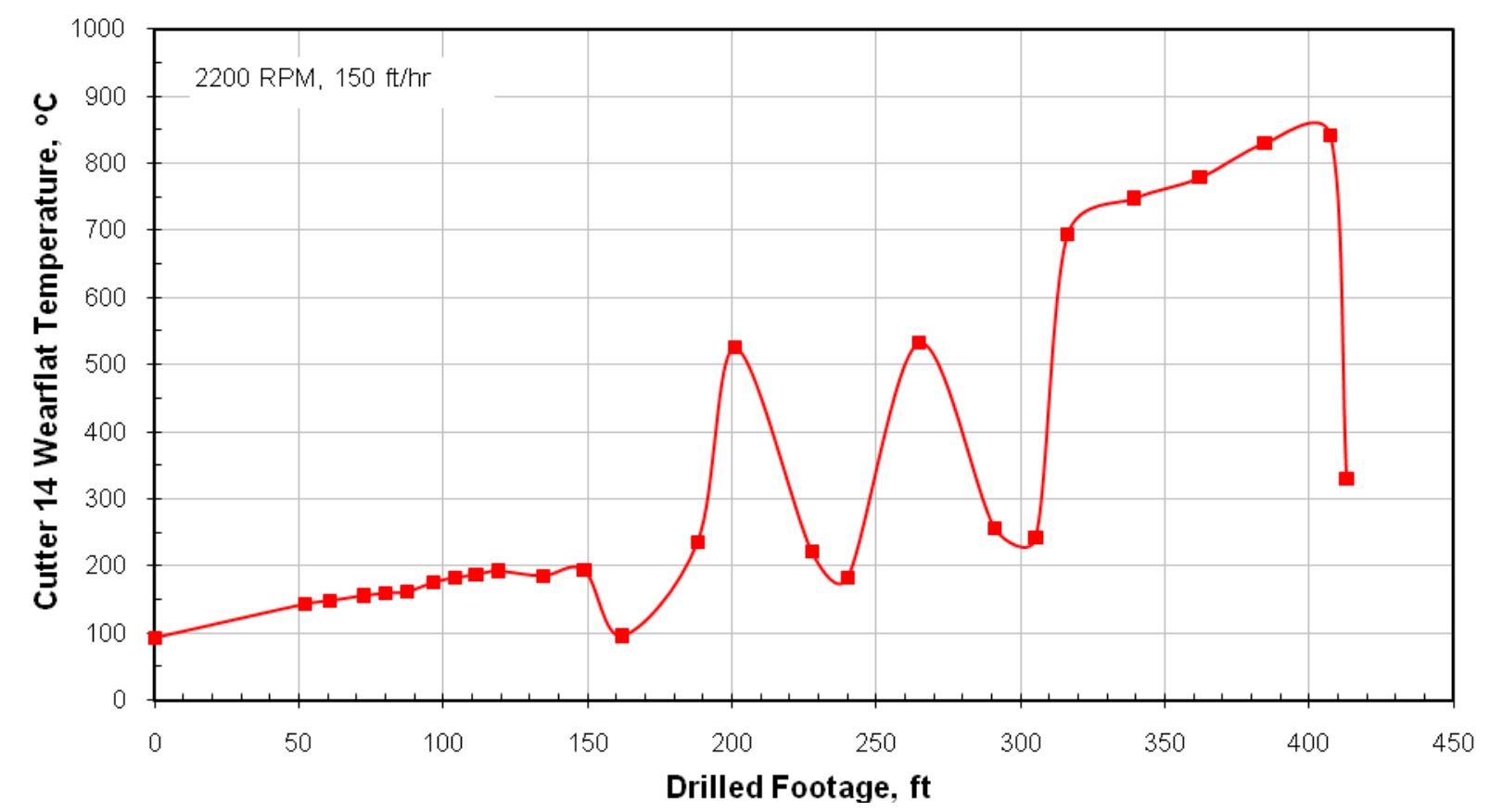

Figure 8: Cutter 14 Wearflat Temperature at 2,200 RPM

Notice how dramatically the cutter temperature can change in just a few feet of drilling. This is because an increased penetrating force will increase both the cutter wear rate and the cutter temperature, according to the models used in PDCWEAR. So the hottest cutter on the bit will tend to also wear faster than surrounding cutters, even without thermally-accelerated effects. Consequently, as the bit further wears, that cutter wears faster and will tend to protrude less and less relative to the surrounding cutters, so that those cutters will eventually share more and more of its load. This leads to lower forces and consequently lower wear rates and lower temperatures for that previously hottest cutter. With a properly designed bit, surrounding cutters will always "compete" for a greater share of the load in this manner, ensuring relatively even wear across the face of the bit.

Figures 9-11 show the calculated bit responses at the three stages of bit wear previously considered. Note that for a given level of cutter wear and WOB, the bit always cuts more rapidly at the higher rotary speed, although its wear rate is also generally higher. Another way to state this is that the higher-speed bit requires much lower WOB to achieve a given ROP. The same can be said of drilling torque. Much lower drilling torque is required to achieve a given ROP at the higher rotary speed. 




Figure 9: ROP response to WOB

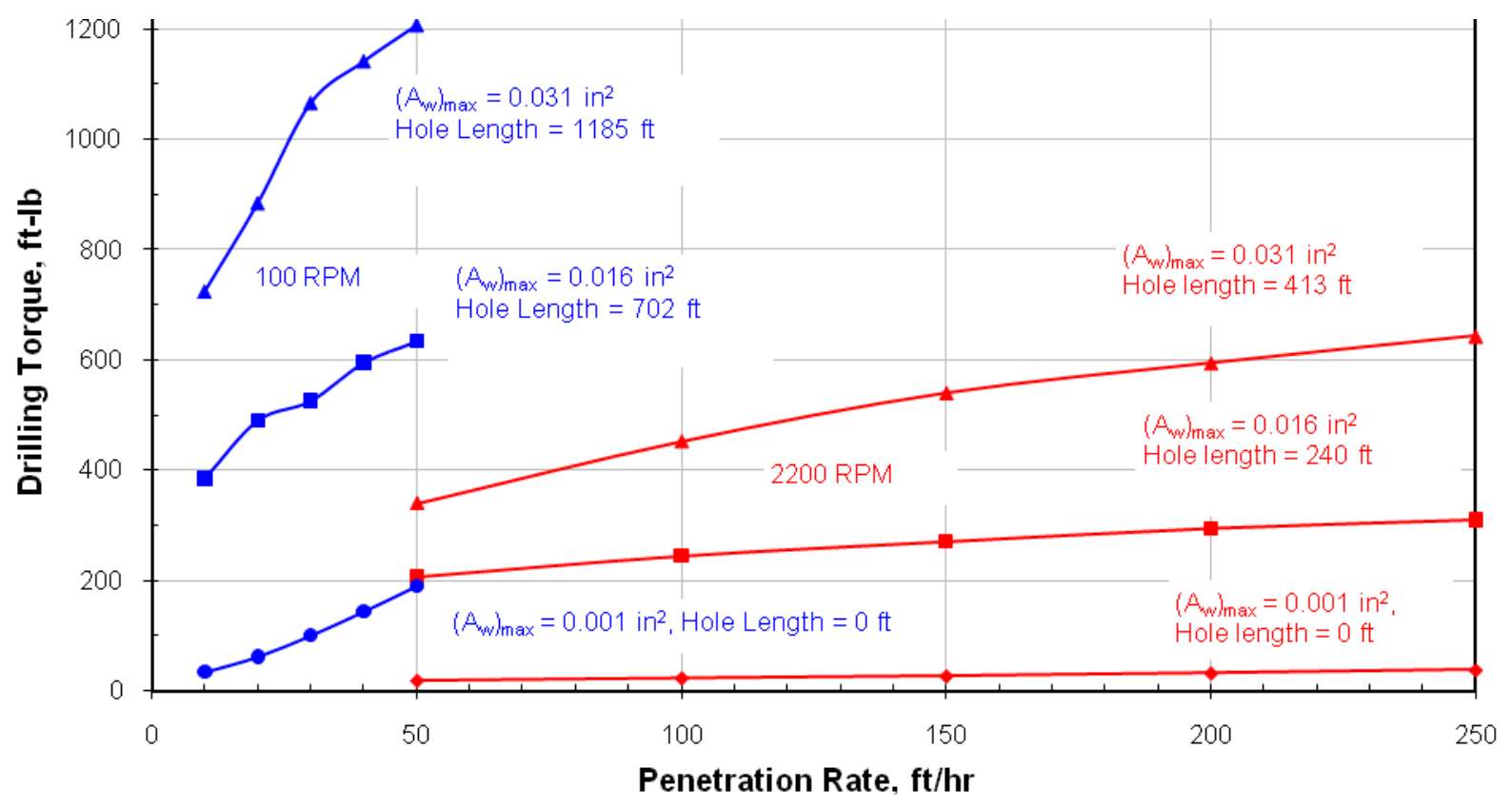

Figure 10: Drilling Torque vs. ROP 




Figure 11: Bit Imbalance-force Ratio (Bit Side Force/WOB)

The bit imbalance-force ratios shown in Figure 11 are the ratio of the calculated bit side force to the weight on bit. In most cases, even when the bit is new, the bit side force is about $10-20 \%$ of the WOB. It reaches over $30 \%$ of the WOB when the bit is rotated at 2,200 RPM and is near the end of its bit life. These imbalance-force ratios seem fairly high and should be reduced by relocating cutters if possible. I was once told (in the early 1990s) that Smith Tool would balance their "ultra-balanced" bits to within $1 \%$ of WOB using their modified version of PDCWEAR.

What fundamentally accounts for the extraordinarily different predictions for the same bit at 100 RPM and 2,200 RPM? Rotary speed plays a role in PDCWEAR in two ways:

1) in the calculation of the individual cutter temperatures; but since the wear model does not currently include thermal effects, these calculated temperatures have no effect on wear in PDCWEAR; and 2) in the calculation of the bit feed rate, which is the amount the bit advances forward with each revolution of the bit.

The bit feed rate is the ratio of ROP to RPM. It is what determines the cutting profile for a given bit and, consequently, the forces on each cutter, the wear rate of each cutter, and the overall bit forces and torque. The low-speed bit in this analysis, at $100 \mathrm{RPM}$ and $30 \mathrm{ft} / \mathrm{hr}$, has a bit feed rate of $0.060 \mathrm{inch} /$ revolution, while the high-speed bit at 2,200 RPM and $150 \mathrm{ft} / \mathrm{hr}$ has a bit feed rate of only $0.014 \mathrm{inch} / \mathrm{revolution}$. The differences in cutting profiles between these two feed rates are significant, as shown in Figures 12 and 13. In these figures, the light blue areas are the profiles of rock cut by each cutter. The size and shape of these cut profiles determine the effective depth of cuts calculated by PDCWEAR, which in turn determine the cutter penetrating forces and all the other parameters those forces affect. 


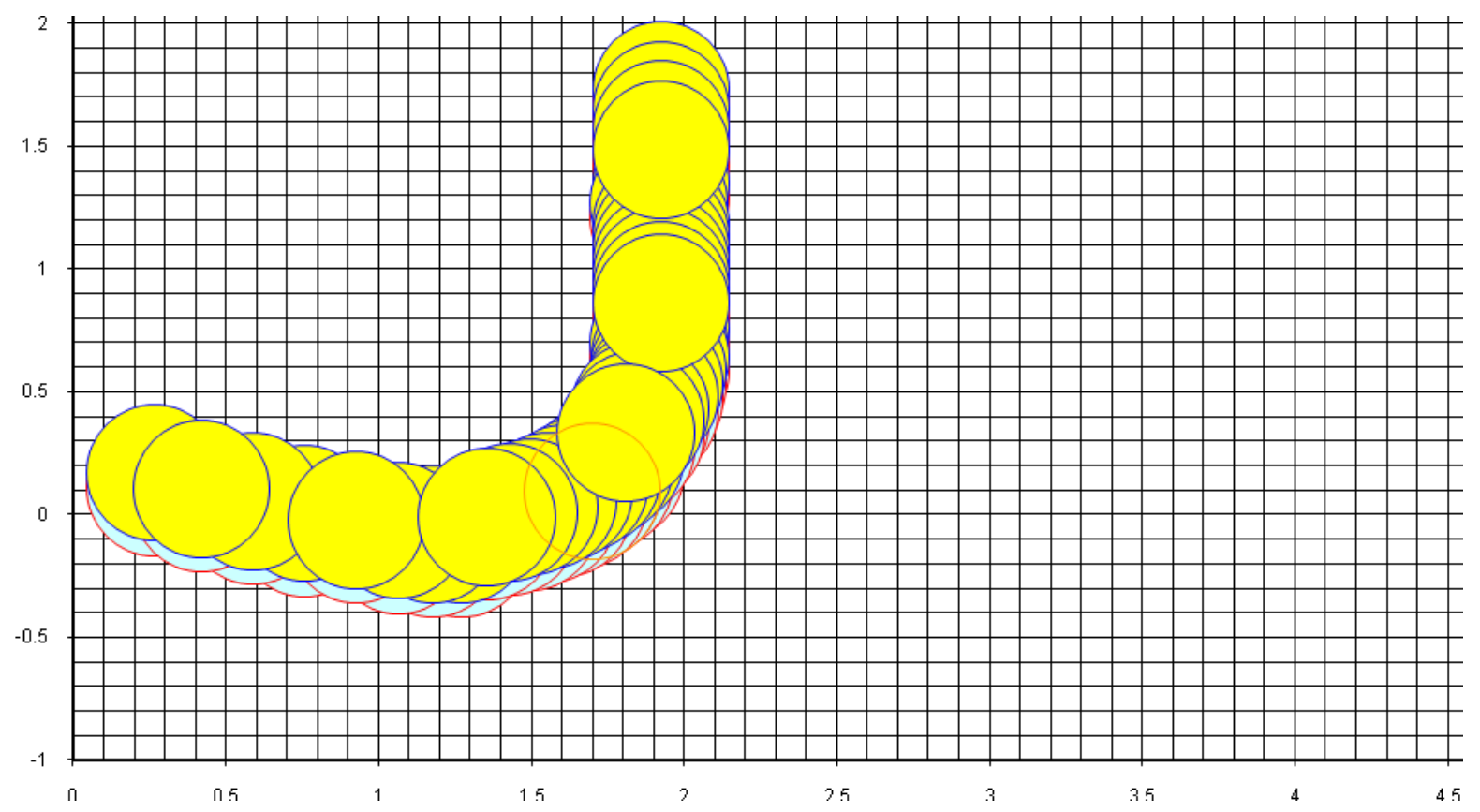

Figure 12: Cutting profiles for drill bit at $100 \mathrm{RPM}, 30 \mathrm{ft} / \mathrm{hr}$ (0.060 inch/revolution)



Figure 13: Cutting profiles for drill bit at $2200 \mathrm{RPM}, 150 \mathrm{ft} / \mathrm{hr}$ (0.014 inch/revolution)

Figure 14 below is a diagram showing a drag cutter on a bit, with all pertinent parameters identified. This is used to describe how frictional heating leads to elevated temperatures throughout the cutter. 


\section{Drag Cutter on a Drill Bit}



Figure 14: Forces on Cutter While Drilling

Figure 15 is a plot of Experimental PDC cutter wear rates vs. cutter wearflat temperature, from Sandia work; describe how wear rates with PDC cutters accelerate above $350^{\circ} \mathrm{C}$ (because of thermal stresses caused by thermal mismatch between diamond and WC) and polycrystalline diamond selfdestructs at temperatures above $750^{\circ} \mathrm{C}$ (because of thermal mismatch between the diamond and cobalt or other catalyst in the polycrystalline diamond); but TSP does not exhibit these problems to the same extent because the TSP layer is thicker and the catalyst has been removed from the microstructure.

\section{PDC Cutter Wear Data}

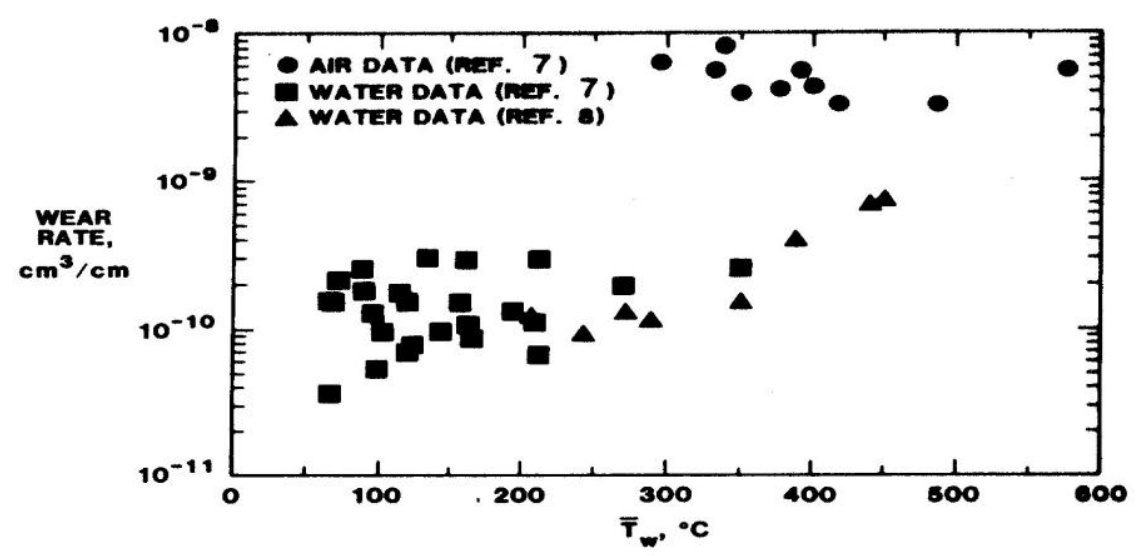

Figure 15: PDC Cutter Wear Rate vs. Temperature

Finite element models of TSP cutter, used four different wearflat configurations as shown in Figure 16 to explain that the largest wearflat extends through the braze line. 


\section{Four Levels of Wear Modeled}

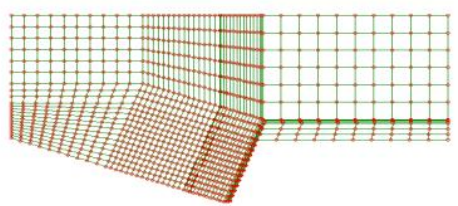

$\mathrm{L}_{\mathrm{w}}=0.38 \mathrm{~mm}$

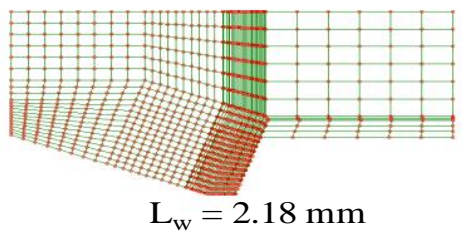



$\mathrm{L}_{\mathrm{w}}=0.68 \mathrm{~mm}$

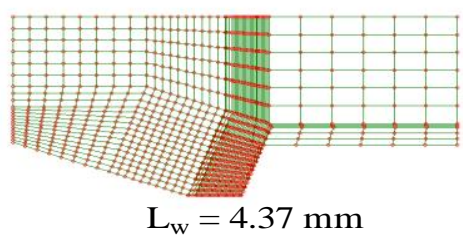

Figure 16: Cutter Wear Flats

The relation between the heat transfer coefficient and flow rate for PDC cutters is shown in Figure 17. The heat transfer coefficients on the order of $1 \mathrm{~W} / \mathrm{cm}^{2}-{ }^{\circ} \mathrm{C}$ are typical when water is the drilling fluid.

\section{Measured Cooling Coefficients for PDC Cutters}

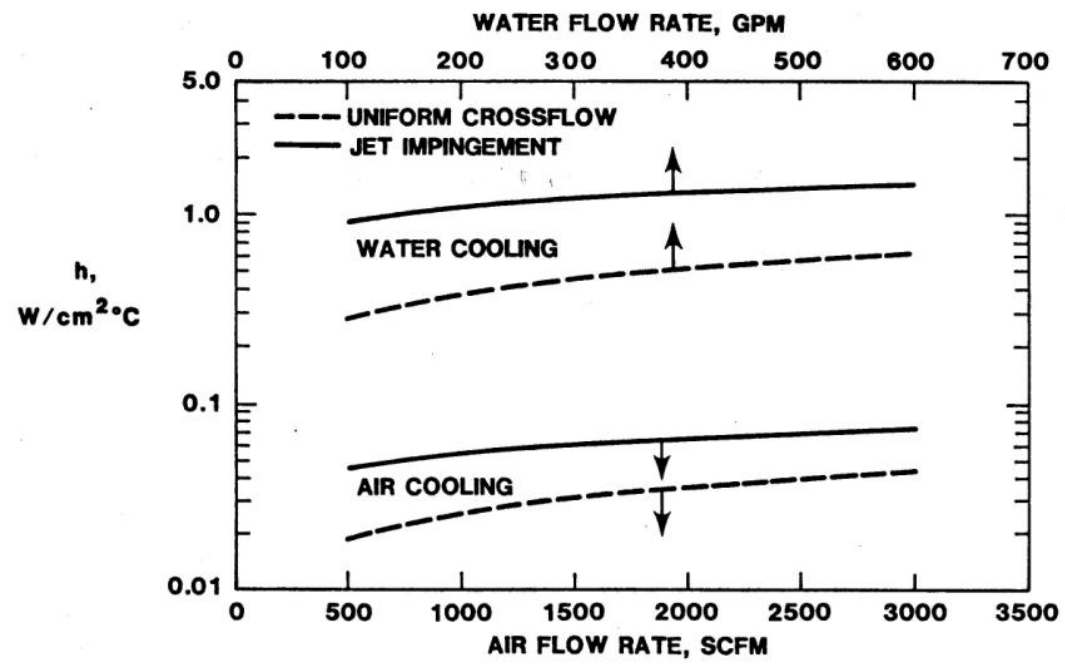

Figure 17: PDC Cutter Cooling Coefficients 
The wearflat heat flux can now be defined. The calculations of the wearflat heat flux listed in Figure 18 show how the possible range can extend from $1 \times 10^{5}$ to $2 \times 10^{9} \mathrm{~W} / \mathrm{m}^{2}$.

\section{Estimating Wearflat Heat Flux}

\begin{tabular}{|c|c|c|c|}
\hline \multicolumn{4}{|c|}{ Total Frictional Heating at Wearflat, $Q=F_{d} V=\mu F V$} \\
\hline \multicolumn{4}{|c|}{ Heat Flow into Cutter Wearflat, $Q_{w}=\alpha Q=\alpha \mu F V$} \\
\hline \multicolumn{4}{|c|}{ Heat Flux into Cutter Wearflat, $\mathrm{q}_{\mathrm{w}}=\mathrm{Q}_{\mathrm{w}} / \mathrm{A}_{\mathrm{w}}=\alpha \mu \mathrm{VF} / \mathrm{A}_{\mathrm{w}}$} \\
\hline \multicolumn{4}{|c|}{ Possible Range in Wearflat Heat Flux } \\
\hline Energy partitioning fraction, $\alpha$ & 0.2 & 0.9 & \\
\hline Friction coefficient, $\mu$ & 0.03 & 0.30 & \\
\hline Cutter velocity, V & 0.5 & 12 & $\mathrm{~m} / \mathrm{sec}$ \\
\hline Cutter penetrating stress, $F / A_{w}$ & 35 & 700 & $\mathrm{MPa}$ \\
\hline Wearflat heat flux, $q_{w}$ & 1.1E+05 & $2.3 \mathrm{E}+09$ & $\mathrm{~W} / \mathrm{m}^{2}$ \\
\hline
\end{tabular}

Figure 18: Cutter Heat Flux

Figure 19 shows colored isotherm plots for one of the FE runs, with thermal gradients throughout the cutter.

\section{Typical FE Temperature Calculations}

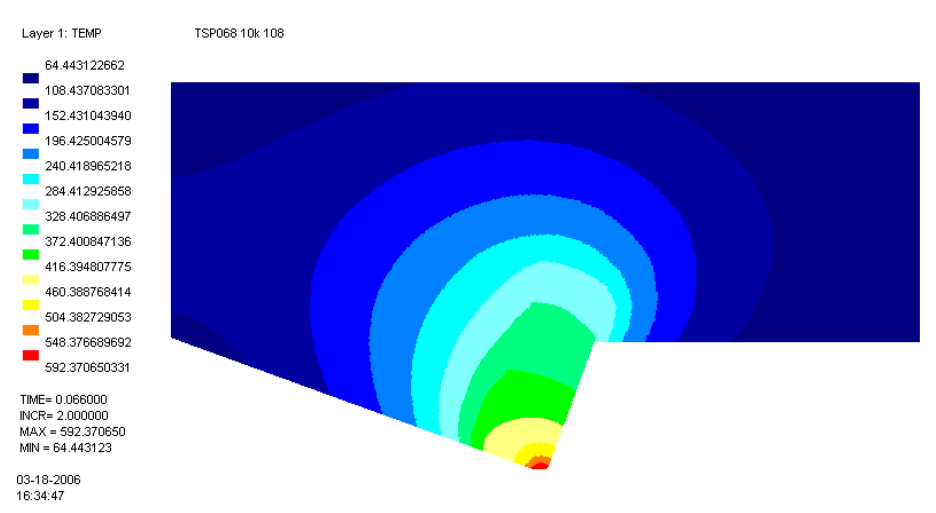

Figure 19: Typical FE Temperature Result 
Curves of calculated $T_{w}-T_{f}$ vs. $q_{w}$ for TSP and PDC cutters using temperature-dependent thermal properties are given in Figure 20. They; show how much cooler a TSP cutter runs because of its thicker diamond layer and higher thermal conductivity.

\section{Calculated Temperatures for TSP and PDC Cutters}



Figure 20: Temperature of TSP and PDC Cutters

Figure 21 demonstrates the affect of rock-chip build-up on the face of the cutter on the cutter temperature. Again, this also shows the lower temperature of the TSP cutter due to its' higher thermal conductivity when compared to the "leached" PDC cutter.

\section{Effects of Rock-Chip Buildup on Diamond Face}

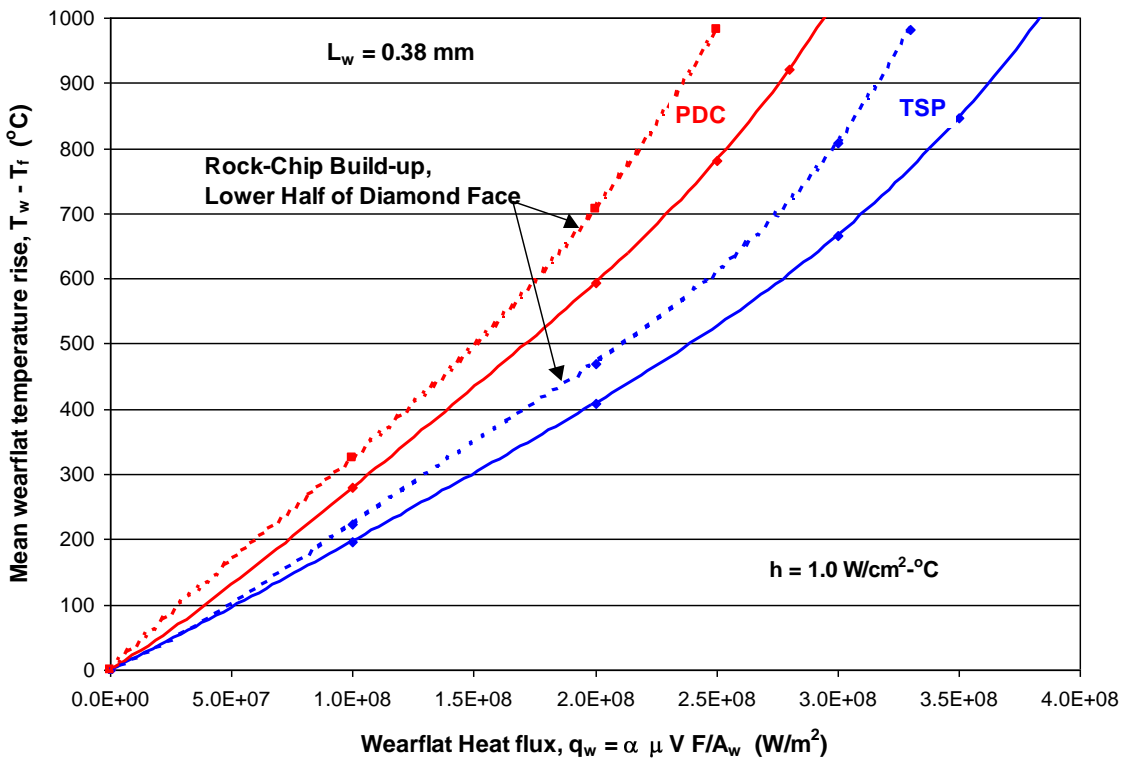

Figure 21: Effect of Rock-Chip Build-up on Temperature 
Figure 22 lists the calculated heat fluxes for gage cutters on two bits: a 7.5-in bit running at 100 RPM; and a 4-1/8 in bit running at $2000 \mathrm{RPM}$, leading to heat fluxes of $2.2 \times 10^{8}$ and $4.6 \times 10^{8} \mathrm{~W} / \mathrm{m}^{2}$, respectively.

\section{Wearflat Heat Flux for Two Bits}

\begin{tabular}{|c|c|c|c|}
\hline \multicolumn{4}{|c|}{ Total Frictional Heating at Wearflat, $Q=F_{d} V=\mu F V$} \\
\hline \multicolumn{4}{|c|}{ Heat Flow into Cutter Wearflat, $Q_{w}=\alpha Q=\alpha \mu F$ V } \\
\hline \multicolumn{4}{|c|}{ Heat Flux into Cutter Wearflat, $q_{w}=Q_{w} / A_{w}=\alpha \mu \vee F / A_{w}$} \\
\hline \multicolumn{3}{|c|}{ Wearflat Heat Flux for Two Bits } & \\
\hline & $\begin{array}{c}\text { 7.5-inch bit } \\
100 \text { RPM }\end{array}$ & $\begin{array}{l}4.125 \text {-inch bit } \\
2000 \text { RPM }\end{array}$ & \\
\hline Energy partitioning fraction, $\alpha$ & 0.81 & 0.56 & \\
\hline Friction coefficient, $\mu$ & 0.09 & 0.05 & \\
\hline Cutter velocity, $\mathrm{V}$ & 1.0 & 11.0 & $\mathrm{~m} / \mathrm{sec}$ \\
\hline Cutter penetrating stress, $F / A_{w}$ & 300 & 100 & $\mathrm{MPa}$ \\
\hline Wearflat heat flux, $q_{w}$ & $2.2 \mathrm{E}+07$ & $3.1 \mathrm{E}+07$ & $\mathrm{~W} / \mathrm{m}^{2}$ \\
\hline
\end{tabular}

Figure 22: Cutter Heat Flux Figure 23 depicts the affect of heat fluxes of $2.2 \times 10^{8}$ and $4.6 \times 10^{8} \mathrm{~W} / \mathrm{m}^{2}$ given in Figure 22 above for both TSP and PDC cutters. The PDC cutter reaches its $350^{\circ} \mathrm{C}$ limit and how thermal issues are not important for the lower heat flux but become dominant at the higher heat flux. The advantage of the TSP cutter is shown as it survives both heat flux levels. Further, the affect of rock chip build-up in front of the cutter as it affects the PDC cutter temperature to a greater degree than the TSP cutter.

\section{Predicted Gage-Cutter Temperatures for Two Bits}

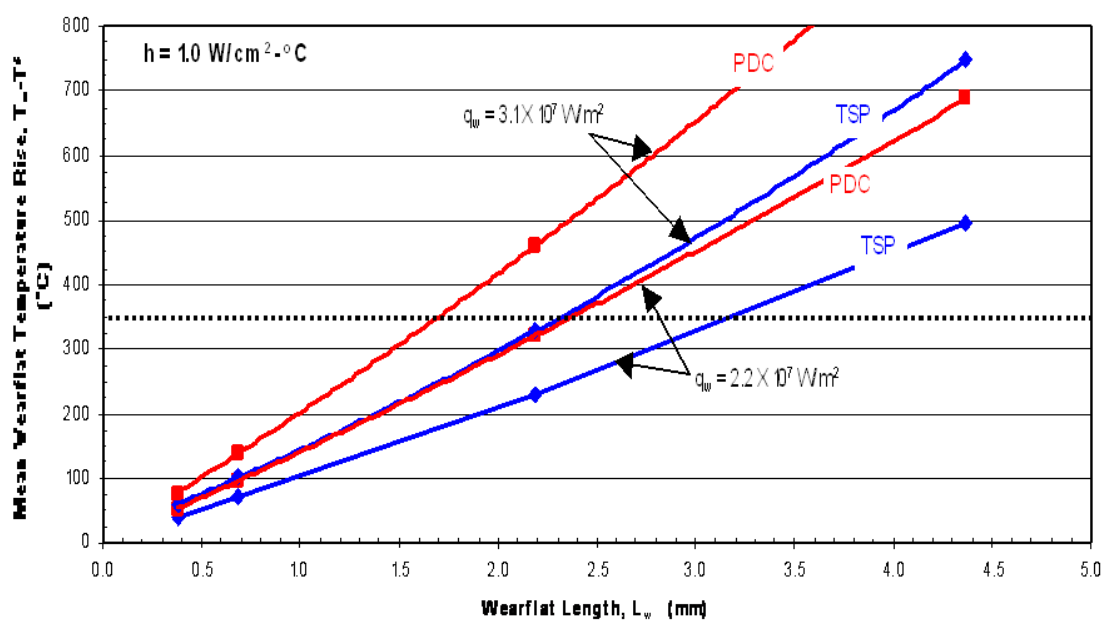

Figure 23: Gage Cutter Temperature 
A snapshot of the DragBit graphical user interface (GUI) is shown in Figure 24. This provided a user friendly interface. This code was used to analyze the 4-1/8 in Turbodrill bits and compare predicted results with drilling performance in the high speed drilling tests at the Terra Tek Drilling Laboratory.

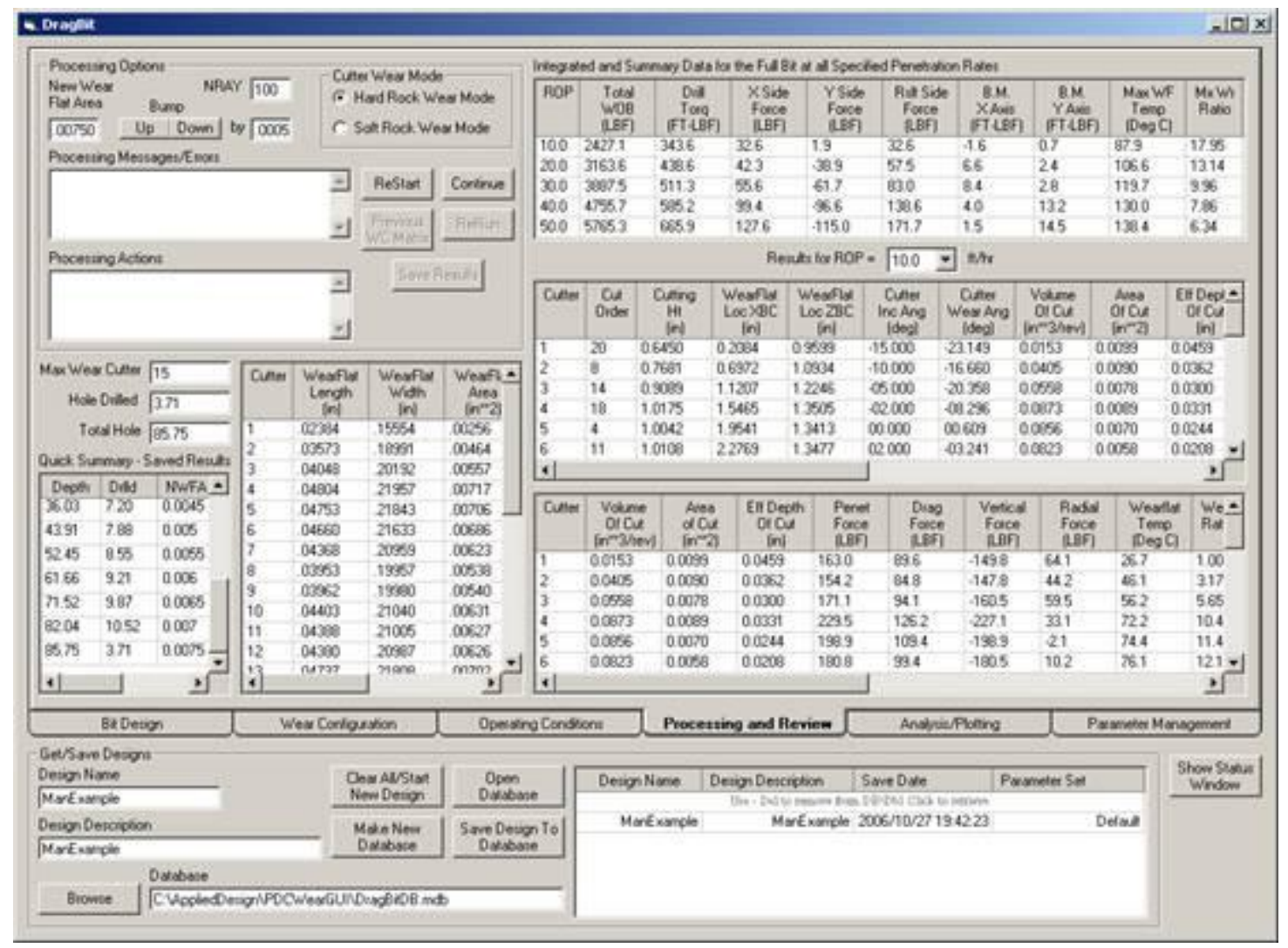

Figure 24: New DragBit Simulator

Contained in the input to DragBit is shown in the schematic in Figure 25 is how cutter forces, temperatures, WOB, and drilling torque are calculated; and how the wearflats increase with simulated footage drilled to predict the drilling performance over the life of the bit. The forces on the cutters are listed as shown in Figure 25. 


\section{Drilling Forces and Moments on a Drag Bit}
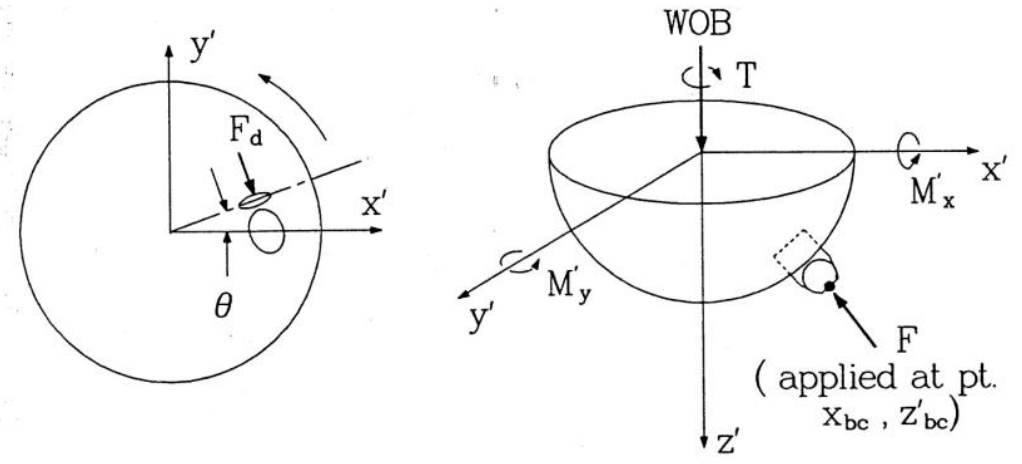

Figure 25: Forces on Cutters While Drilling

Input of the effective depth of cut is illustrated in Figure 26.

\section{Effective Depth of Cut}

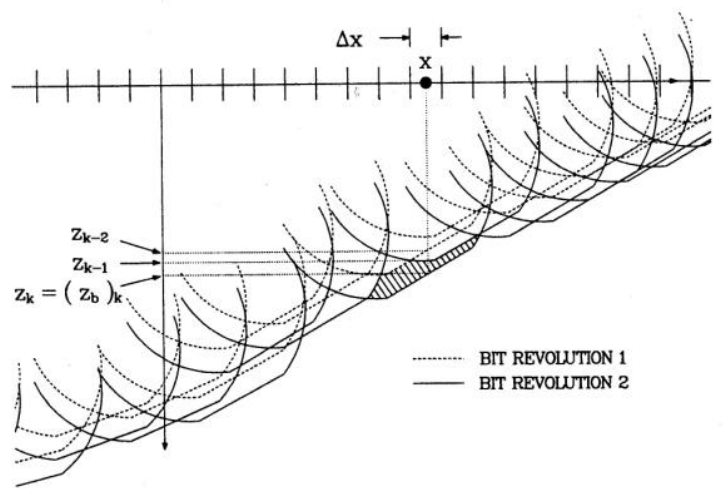

Figure 26: Effective Depth of Cut

The resulting stress calculated by the code are illustrated in Figure 27 


\section{Measured Single-Cutter Penetrating Stresses}

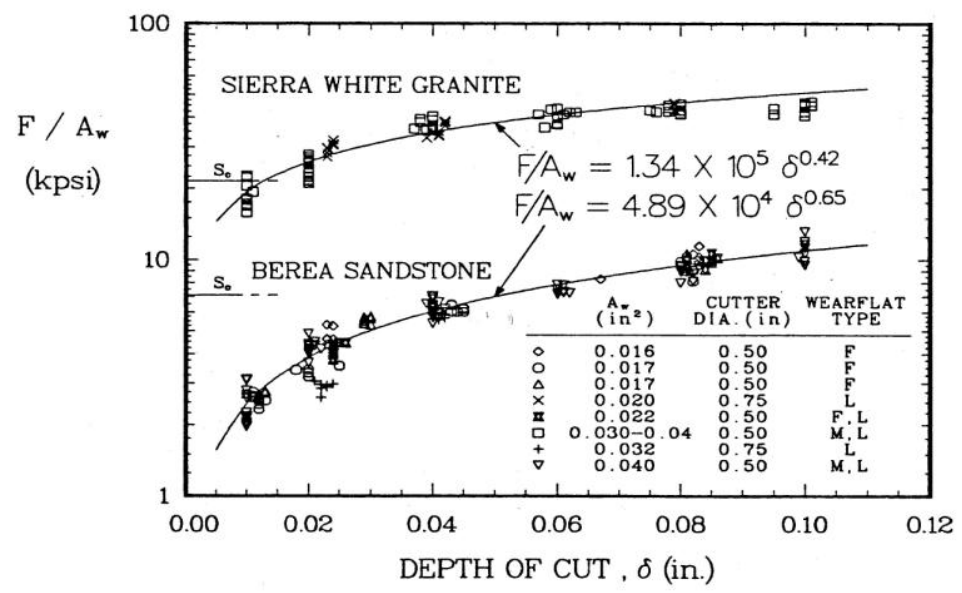

Figure 27: Cutter Penetrating Stresses

The DragBit codes allowed both PDC and TSP drill bits to be run in virtual space for the conditions expected during project at Catoosa field test well and the Terra Tek Drilling Laboratory. The new DragBit Code was exercised in a parametric study to characterize the performance of different TSP bits under the high-speed conditions anticipated for this project. Parameters such as the number, size, and location of TSP cutters, the bit diameter, profile, and hydraulic design, the bit rotary speed, rock type, weight-on-bit, and cooling fluid temperature was varied in a methodical manner. The performance and wear of the bits under these various conditions was characterized and compared in order to develop general guidelines for the design and operation of TSP bits in this application. These results are valuable for designing the final TSP bit or bits used in this project, but also for providing insight into TSP bit design rules for other applications.

The Smith Bit design employing PDC and TSP cutters built with the support of the DragBit code was used to predict the performance and wear of these specific designs under the anticipated test conditions. The use of PDC and TSP bit design principles based on years of experience, coupled with the powerfully predictive capabilities of the modified design code, enabled the design team to develop a robust methodology for designing high-speed TSP bits for this and other applications.

This iterative process provided a rigorous method for optimizing the bit design in order to achieve its maximum potential performance with minimal wear. It saved significant time and money by allowing any potential design problems to be identified and corrected before actually building the physical bit. Finally, the code provided a prediction of the bit performance and wear that can be used to gauge the effectiveness and accuracy of the numerical modelling effort and the resulting TSP bit design code.

\section{Catoosa Field Test}

Commercial Turbodrill and drill bit hardware for drilling 4-1/8 in diameter hole using existing Turbodrilling and drill bit technology were used to establish "benchmark" performance at the GTI Catoosa Test Site using jointed drill pipe and a downhole assembly to simulate coiled tubing drilling. 
The downhole assembly included a commercial Smith Neyrfor 2-7/8 in directional Turbodrill and an "aggressive" Smith 4-1/8 in fixed cutter drill bit specifically designed with TSP cutters for coiled tubing drilling. The Turbodrill section for the baseline case rotated at 1,100 to 2,000 RPM depending on mud weight, pressure drop, and flow rate.

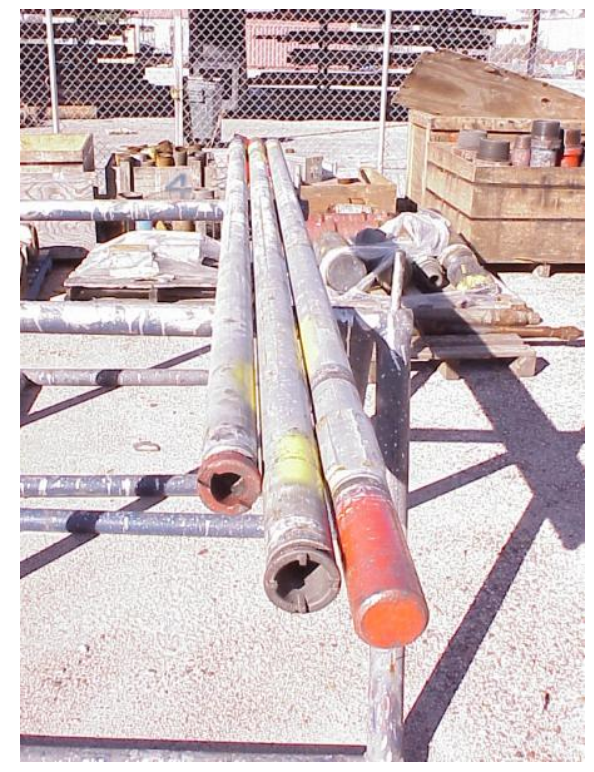

Figure 28: The Turbodrills for the Catoosa Test

Custom, purpose-built drill bits shown in Figures 29 and 30 were designed to be run with the 2-7/8 in prototype Turbodrill. A custom-designed drill bit incorporating the latest available high-performance TSP materials, state-of-the-art matrix powders for the body, optimized hydraulics and optimized cutter layouts based on computerized modelling were designed. A 4-1/8 in PDC bit with TSP cutters and Turbine sleeve, and a 4-1/8 in impregnated diamond bit were tested at the GTI Catoosa, OK field test. The expected performance of the 2-7/8 in Turbodrill and drill bits was achieved.
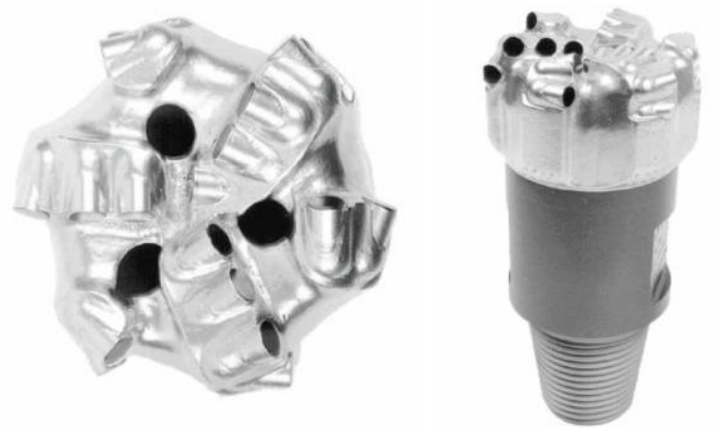

Figure 29: Fixed Cutter 4-1/8" Bit for Coiled Tubing Drilling
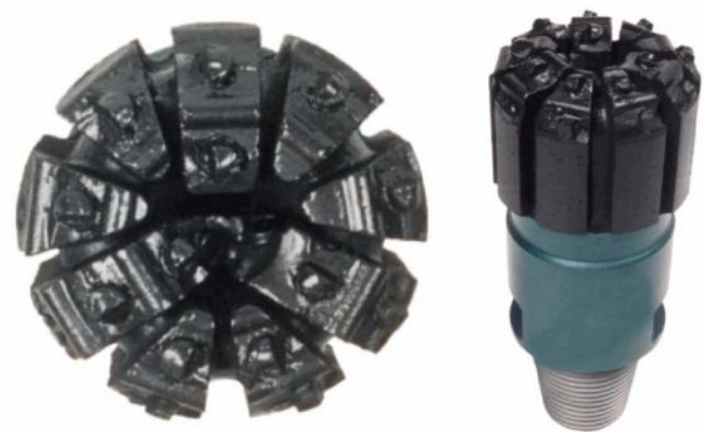

Figure 30: Impregnated 4-1/8" Bit for Coiled Tubing Drilling 


\section{Terra Tek Laboratory Drilling Tests}

Tests of prototype hardware were conducted at the Terra Tek Drilling Laboratory. Smith Neyrfor built two prototype 2-7/8 in Turbodrills using three turbine blade types - NASA, HEAT ${ }^{\mathrm{TM}}$, and Standard Mk2 (one more than initially proposed for this project) for drilling 4-1/8 in diameter hole. Improved thermally stable cutters were prepared for the laboratory test of the Turbodrills. To evaluate the NASA blades, 100 newly designed stators and 100 rotors were built. The downhole assemblies included the Turbodrills employing the three blade type fixed cutter drill bits.

The Turbodrills were attached below the test rig and atmospheric drilling was run in the drilling cellar. Support bushings were provided to stabilize the drill string. An engineering layout of the test setup is in Figure 31 and a photograph of the motor installation is shown in Figure 32. The rock is supported at the base of the drilling stand and drilling fluids with cuttings return to the mud pit. The rock is at atmospheric condition during drilling.

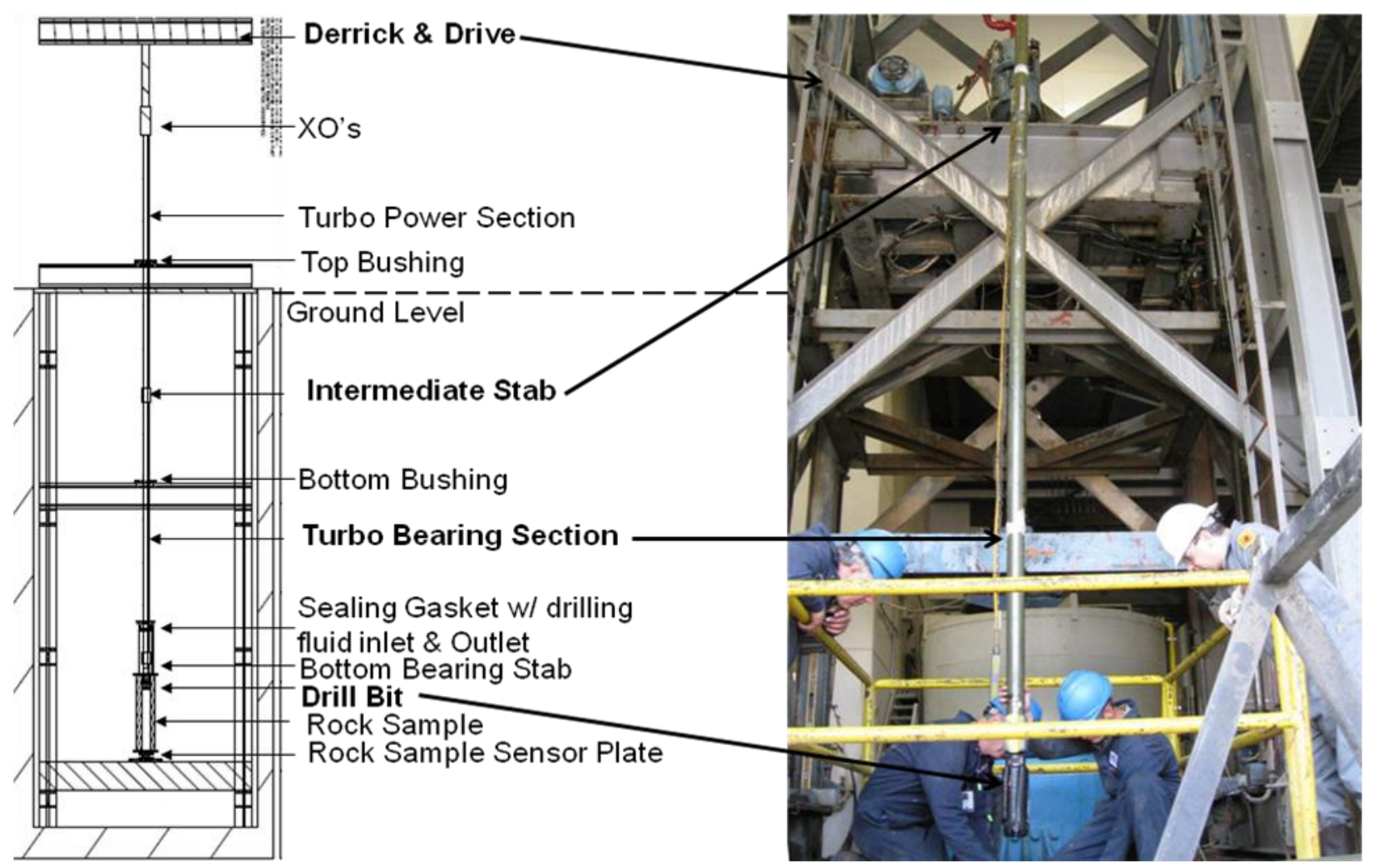

Figure 31: Terra Tek Turbodrill Drilling Simulator 


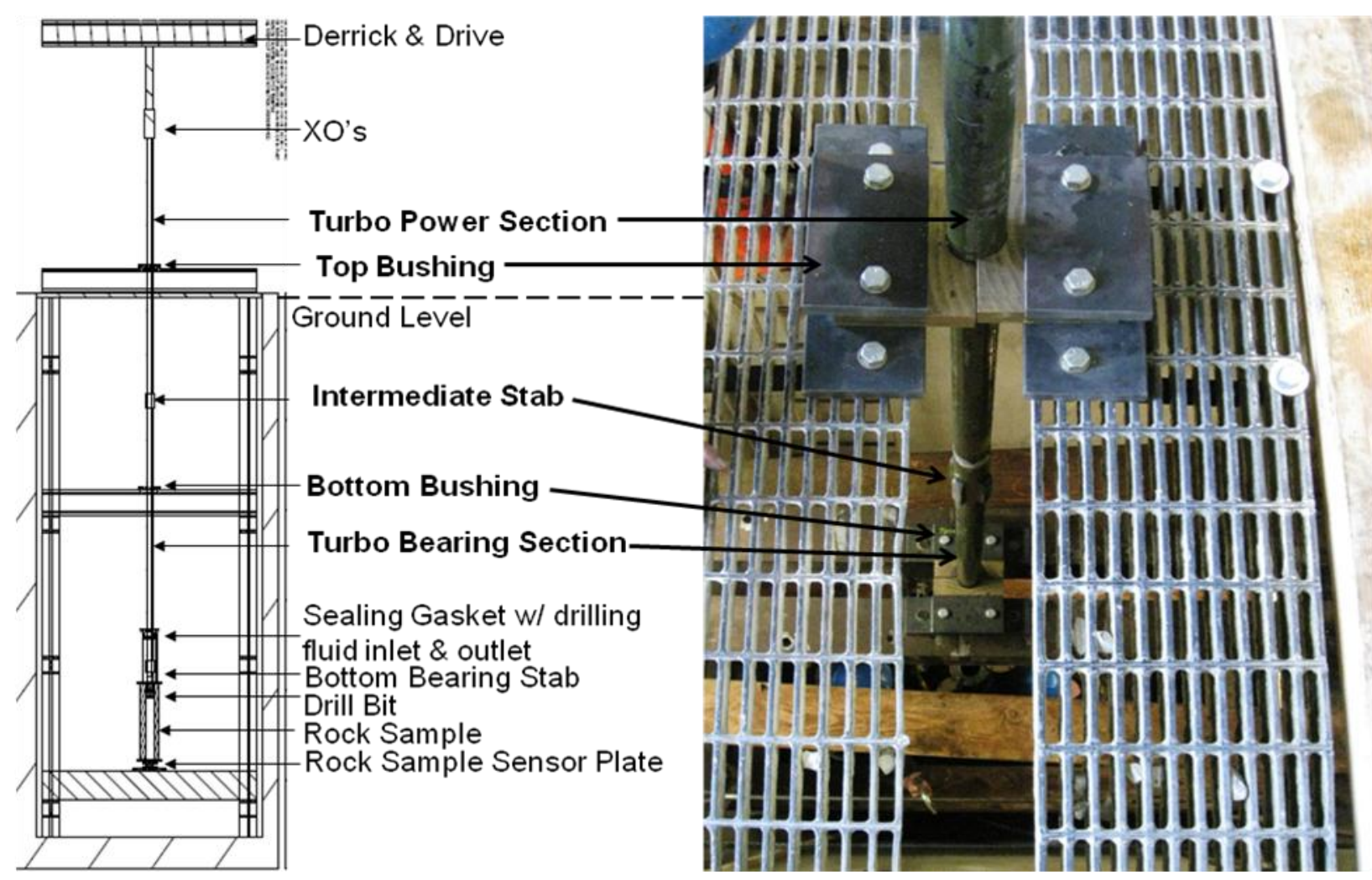

Figure 32: Turbodrill Power Section

\section{Instrumentation, Controls, and Data Acquisition}

Instrumentation used during the testing includes: load cell (for weight on bit), torque cell, bit displacement, rotational speed, and flow rate. Budget constraints limited the system to manual control. Data was collected at about $8 \mathrm{~Hz}$ over entire test sequences.

\section{Test Parameters}

The original test parameters that were to be used during the testing are provided in Table 1.

Table 1: Test matrix showing the turbine, bit, rock, and flow and WOB used for each test

\begin{tabular}{|c|l|c|l|l|c|}
\hline Test & Turbine & Bit & \multicolumn{1}{|c|}{ Rock } & Mud Flow & WOB \\
\hline 1 & NASA & Impregnated & Sierra White granite & $80,90,100,110,120$ & $550,1100,1650$ \\
\hline 2 & NASA & Impregnated & Crab Orchard sandstone & $80,90,100,110,120$ & $550,1100,1650$ \\
\hline 3 & NASA & TSP & Crab Orchard sandstone & $80,90,100,110,120$ & $550,1100,1650$ \\
\hline 4 & NASA & TSP & Sierra White granite & $80,90,100,110,120$ & $550,1100,1650$ \\
\hline 5 & HEAT & Impregnated & Crab Orchard sandstone & $80,90,100,110,120$ & $550,1100,1650$ \\
\hline
\end{tabular}




\begin{tabular}{|c|l|c|l|l|l|}
\hline 6 & HEAT & Impregnated & Sierra White granite & $80,90,100,110,120$ & $550,1100,1650$ \\
\hline 7 & Mk2 & TSP & Crab Orchard sandstone & $80,90,100,110,120$ & $550,1100,1650$ \\
\hline 7 & Mk2 & TSP & Sierra White granite & $80,90,100,110,120$ & $550,1100,1650$ \\
\hline
\end{tabular}

Note: Tests of the Mk2 Standard turbine with the impregnated bit were cancelled because of bit wear and time constraints.

\section{Test Rocks}

Crab Orchard sandstone and Sierra White granite were the two test rocks. The properties of the rock used in this test program are listed in Table 2 Rock cylinders of the Crab Orchard sandstone and Sierra White granite were prepared $15-1 / 2$ in diameters by 36 in long. Figure 33, below, is a photograph of a rock sample installed in the drilling cellar. For the test frame, rock samples approximately 9 in $\mathrm{x} 9$ in $\mathrm{x}$ 24 in were prepared by cutting the rocks such that the bedding planes were parallel to the face where the rock was to be drilled.

Table 2: Test Rock Physical Properties

\begin{tabular}{|l|c|c|}
\hline \multicolumn{1}{|c|}{ Property } & $\begin{array}{c}\text { Sierra White } \\
\text { Granite }\end{array}$ & $\begin{array}{c}\text { Colton } \\
\text { Sandstone }\end{array}$ \\
\hline $\begin{array}{l}\text { Unconfined } \\
\text { Compressive Strength, (psi) }\end{array}$ & 28,000 & 7,600 \\
\hline Porosity (volume \%) & $<1$ & 11 \\
\hline Permeability (md) & Negligible & $1-4$ \\
\hline Bulk Density (g/cc) & 2.65 & 2.65 \\
\hline Grain Density (g/cc) & --- & 2.38 \\
\hline
\end{tabular}




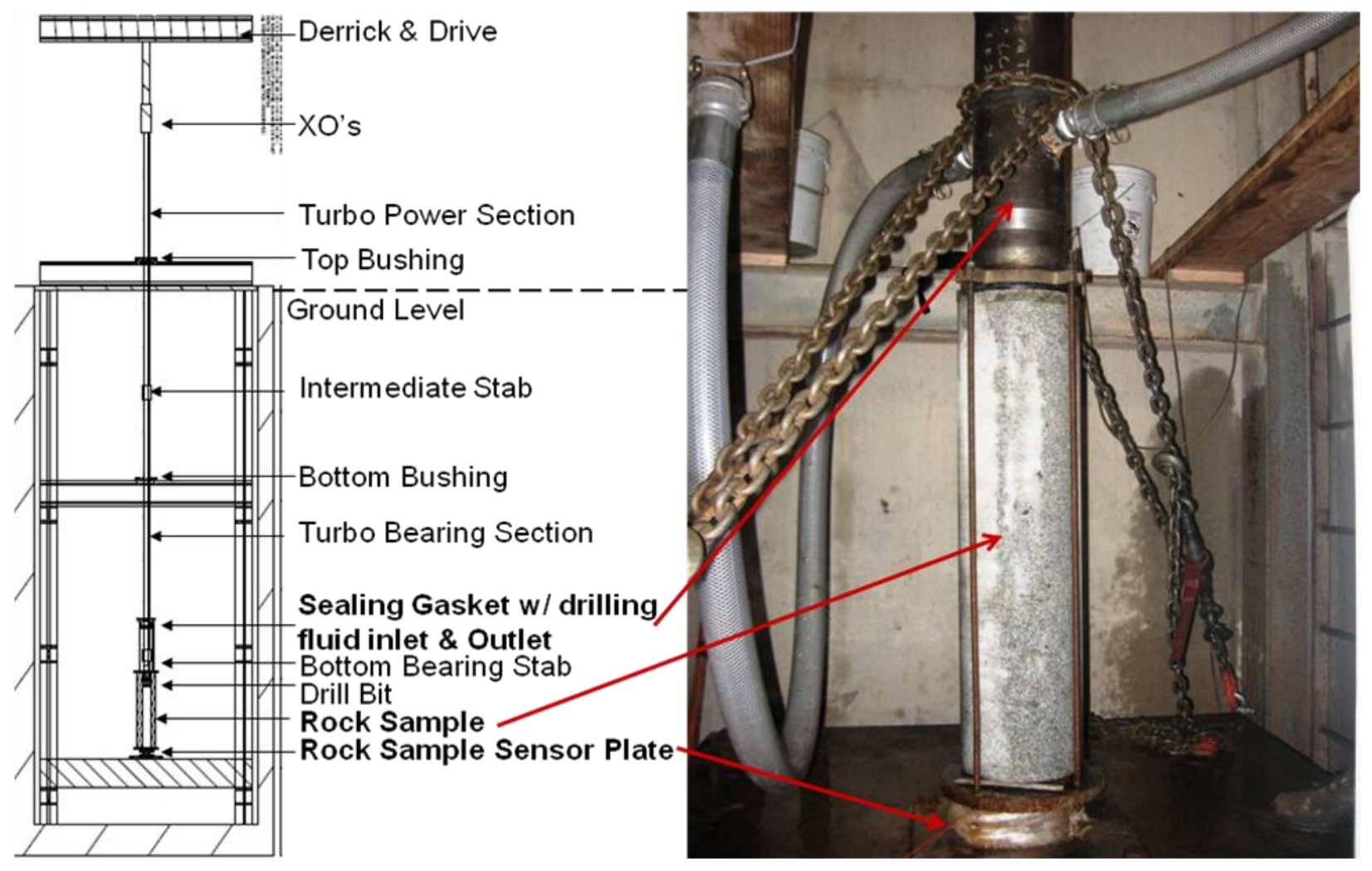

Figure 33: Test Rock

\section{Test Results}

The objective of the Turbodrill laboratory testing was to determine the relative performance of three blade types, NASA, HEAT, and Mk2, in a 2-7/8 in. diameter Turbodrill. To do this, the motors were inspected and flow tested at the Smith Neyrfor laboratory to verify proper performance at Terra Tek. The result was to measure the runaway (no load) RPMs generated by each blade type. The Terra Tek drilling simulator results are illustrated on a graph that plots the power, torque, and RPM versus the motor RPM. A typical graph result is shown in Figure 34 for the NASA bladed Turbodrill drilling sandstone with the PDC cutter drill bit. 


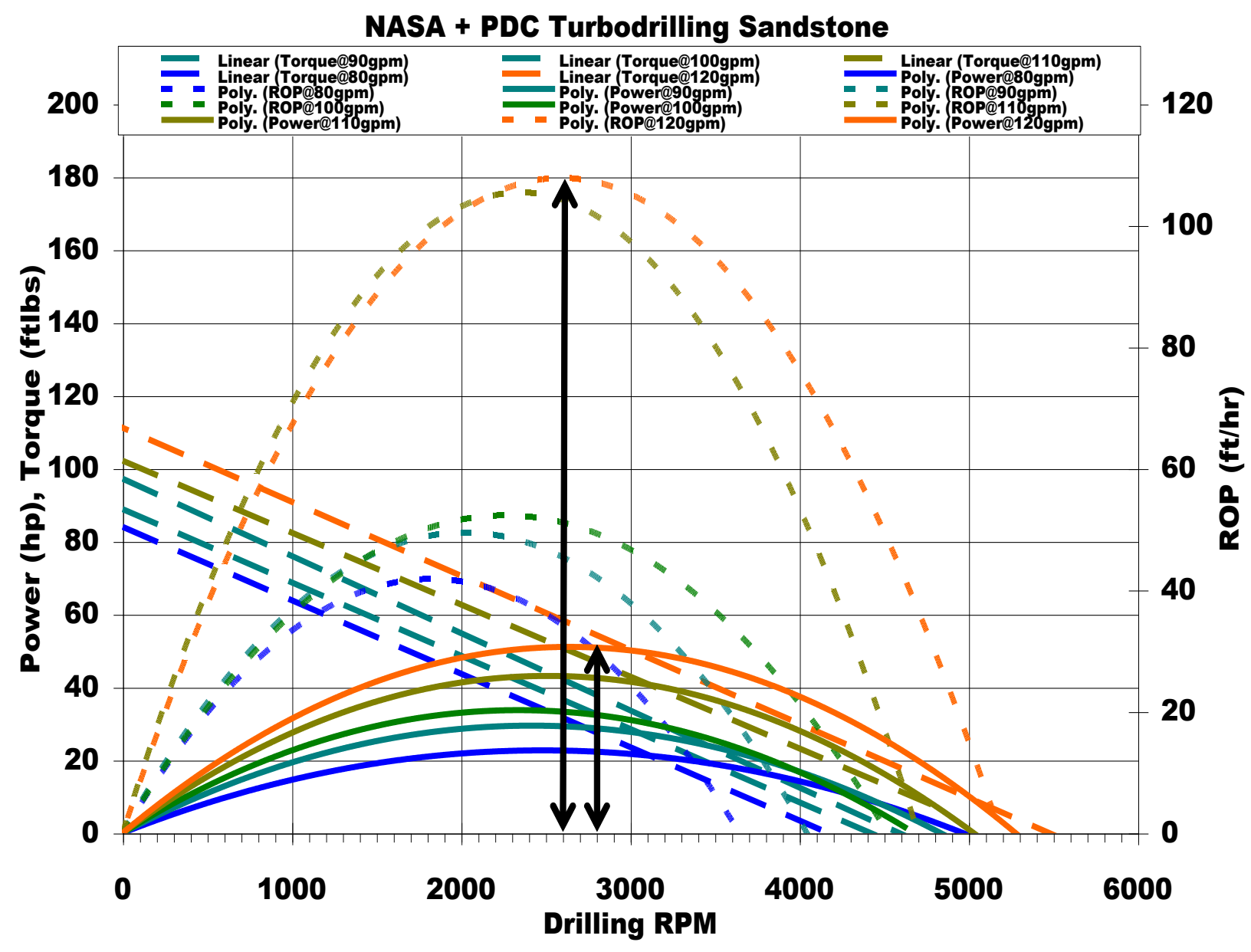

Figure 34: Typical Turbodrilling Test Data

From these data, the relative performance of the Turbodrill when compared to the theoretical and estimated models was calculated and reported herein for each Turbodrill, rock, and drill bit combination tested. As noted, Tests 7 through 10 were not completed.

In Figure 34 above, the upper vertical arrow represents the maximum RPM and the lower arrow is the maximum power for each of the tests reported below.

The test matrix is shown in Table 3.

Table 3: Planned Test Operating Parameters

\begin{tabular}{|l|l|l|l|l|l|}
\hline Test & Turbine & Drill Bit & \multicolumn{1}{|c|}{ Rock Type } & Mud Flow & WOB \\
\hline 1 & NASA & Impregnated & Sierra White Granite & $80,90,100,110,120$ & $550,1100,1650$ \\
\hline 2 & NASA & Impregnated & Crab Orchard Sandstone & $80,90,100,110,120$ & $550,1100,1650$ \\
\hline 3 & NASA & PDC/TSP & Sierra White Granite & $80,90,100,110,120$ & $550,1100,1650$ \\
\hline 4 & NASA & PDC/TSP & Crab Orchard Sandstone & $80,90,100,110,120$ & $550,1100,1650$ \\
\hline
\end{tabular}




\begin{tabular}{|l|l|l|l|l|l|}
\hline 5 & HEAT & Impregnated & Crab Orchard Sandstone & $80,90,100,110,120$ & $550,1100,1650$ \\
\hline 6 & HEAT & Impregnated & Crab Orchard Sandstone & $80,90,100,110,120$ & $550,1100,1650$ \\
\hline 7 & HEAT & PDC/TSP & Sierra White Granite & $80,90,100,110,120$ & $550,1100,1650$ \\
\hline 8 & HEAT & PDC/TSP & Crab Orchard Sandstone & $80,90,100,110,120$ & $550,1100,1650$ \\
\hline 9 & STD & Impregnated & Sierra White Granite & $80,90,100,110,120$ & $550,1100,1650$ \\
\hline 10 & STD & Impregnated & Crab Orchard Sandstone & $80,90,100,110,120$ & $550,1100,1650$ \\
\hline 11 & STD & PDC/TSP & Sierra White Granite & $80,90,100,110,120$ & $550,1100,1650$ \\
\hline 12 & STD & PDC/TSP & Crab Orchard Sandstone & $80,90,100,110,120$ & $550,1100,1650$ \\
\hline
\end{tabular}

\section{Test 1- NASA Blade Turbodrill Drilling White Sierra Granite with an Impregnated Diamond Drill Bit}

In Figure 35 below, data provided the determination that there was a 1-2\% increase in RPM when compared to the theoretical and a $34 \%$ increase when compared to that estimated. Further, there was an $8 \%$ decrease in torque when compared to the theoretical, and a $26 \%$ increase when compared to that estimated. The granite hole pattern had near perfect hole quality, as shown in Figure 36 below. The impregnated drill bit was in "nearly new" condition after the test, as shown in Figure 37 below. The power curves are the theoretical and measured torque values. The sloping lines are the theoretical and measured torque values.

NASA + IMPREG Turbodrilling Granite

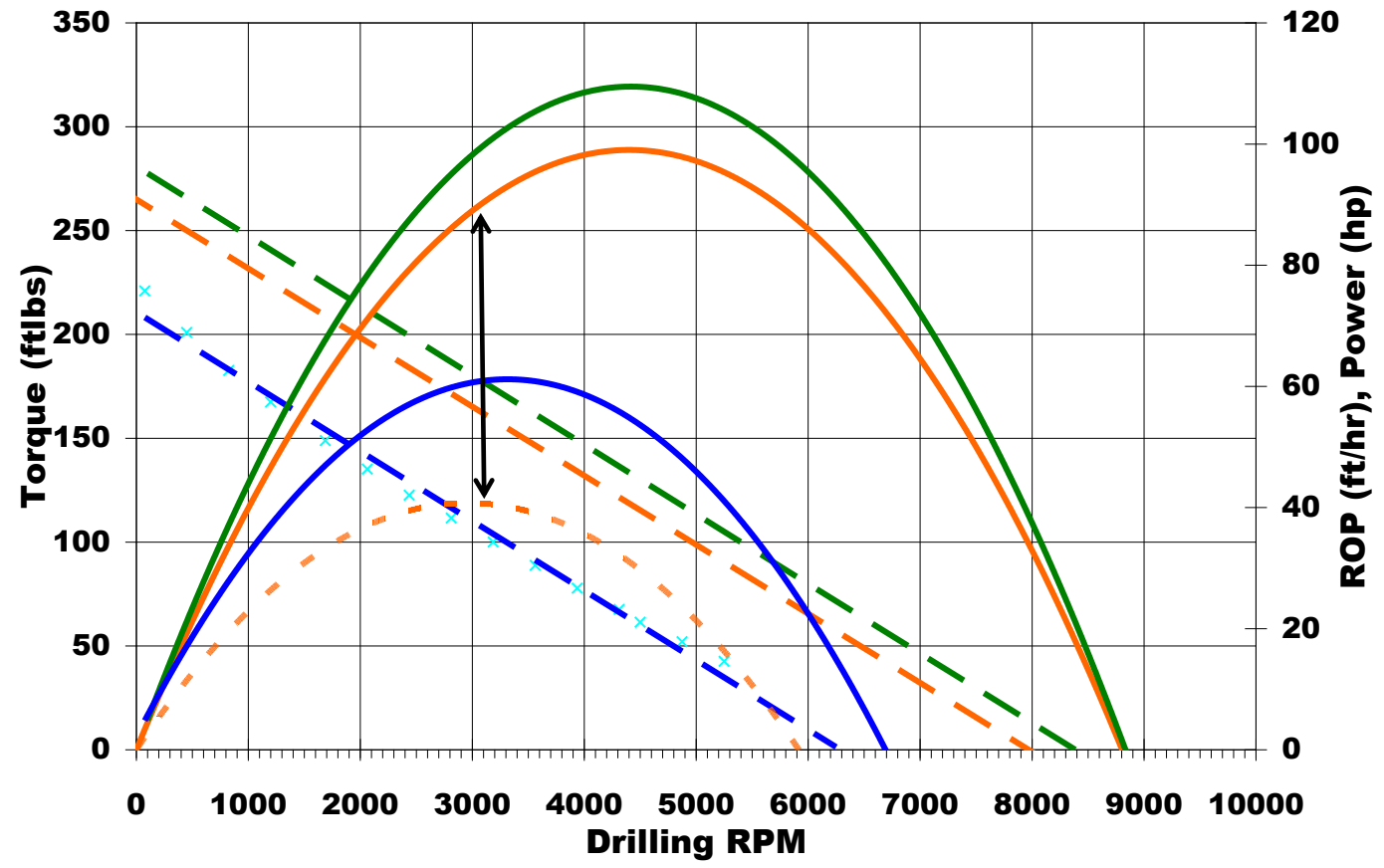

Figure 35: Test 1 Turbodrilling Test Data 


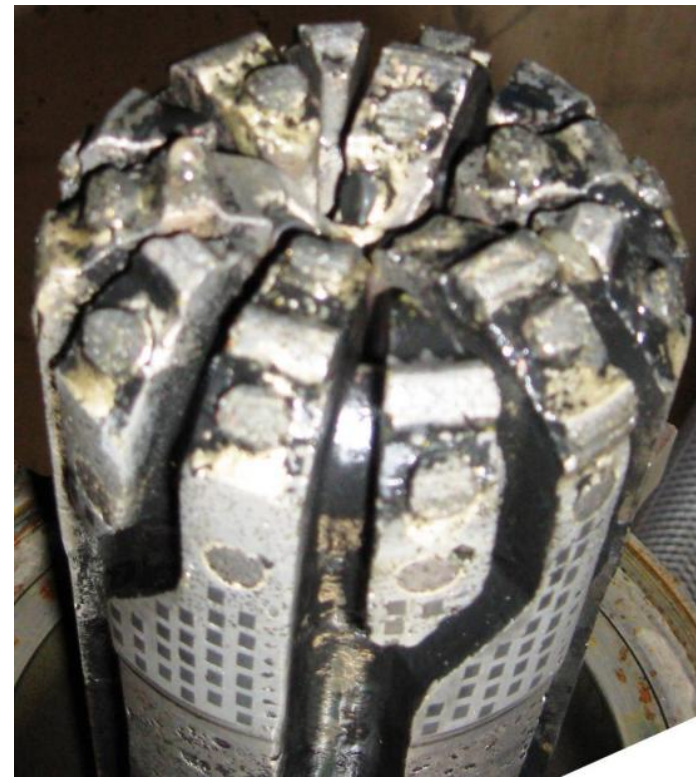

Figure 36: Test 1 Nearly Perfect Borehole

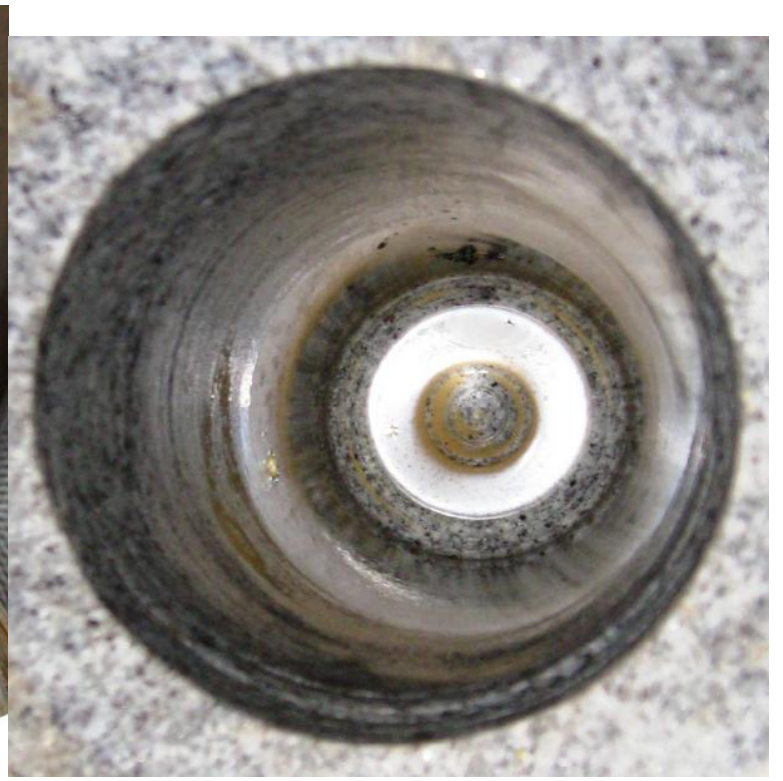

Figure 37: Test 1 Drill Bit After Test

\section{Test 2- NASA Blade Turbodrill Drilling Sandstone with an Impregnated Diamond Drill Bit}

As determined by the data in Figure 38 below, there was a 38\% reduction in RPM when compared to the theoretical value, and a $15 \%$ reduction when compared to the estimated. The torque was $64 \%$ less than theoretical, and $52 \%$ less than the estimated.



Figure 38: Test 2 Turbodrilling Test Data 
Test data was scattered at al flow rates due to the movement of the rock support structure.

The hole drilled in the sandstone shown in Figure 39 below had perfect hole quality.

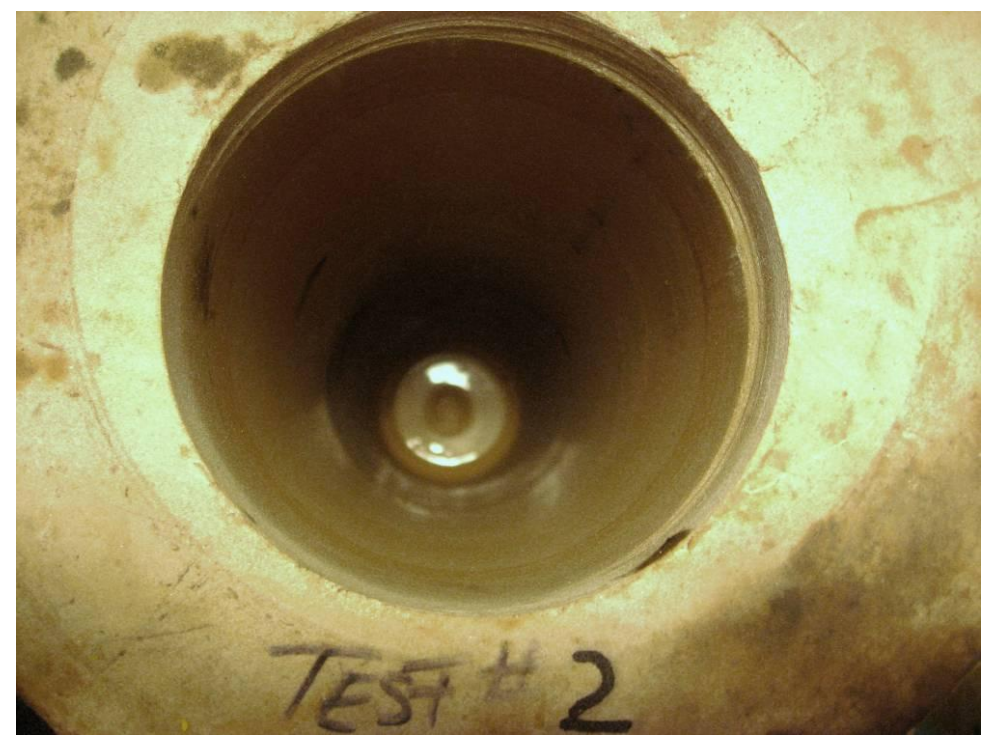

Figure 39: Test 2 Nearly Perfect Borehole

\section{Test 3- NASA Blade Turbodrill Drilling White Sierra Granite with a PDC Drill Bit}

As determined by the data in Figure 40 below, there was a 15\% reduction in RPM when compared to the theoretical value, and an $11 \%$ reduction when compared to the estimated. The torque was $52 \%$ less than theoretical, and $38 \%$ less than the estimated.

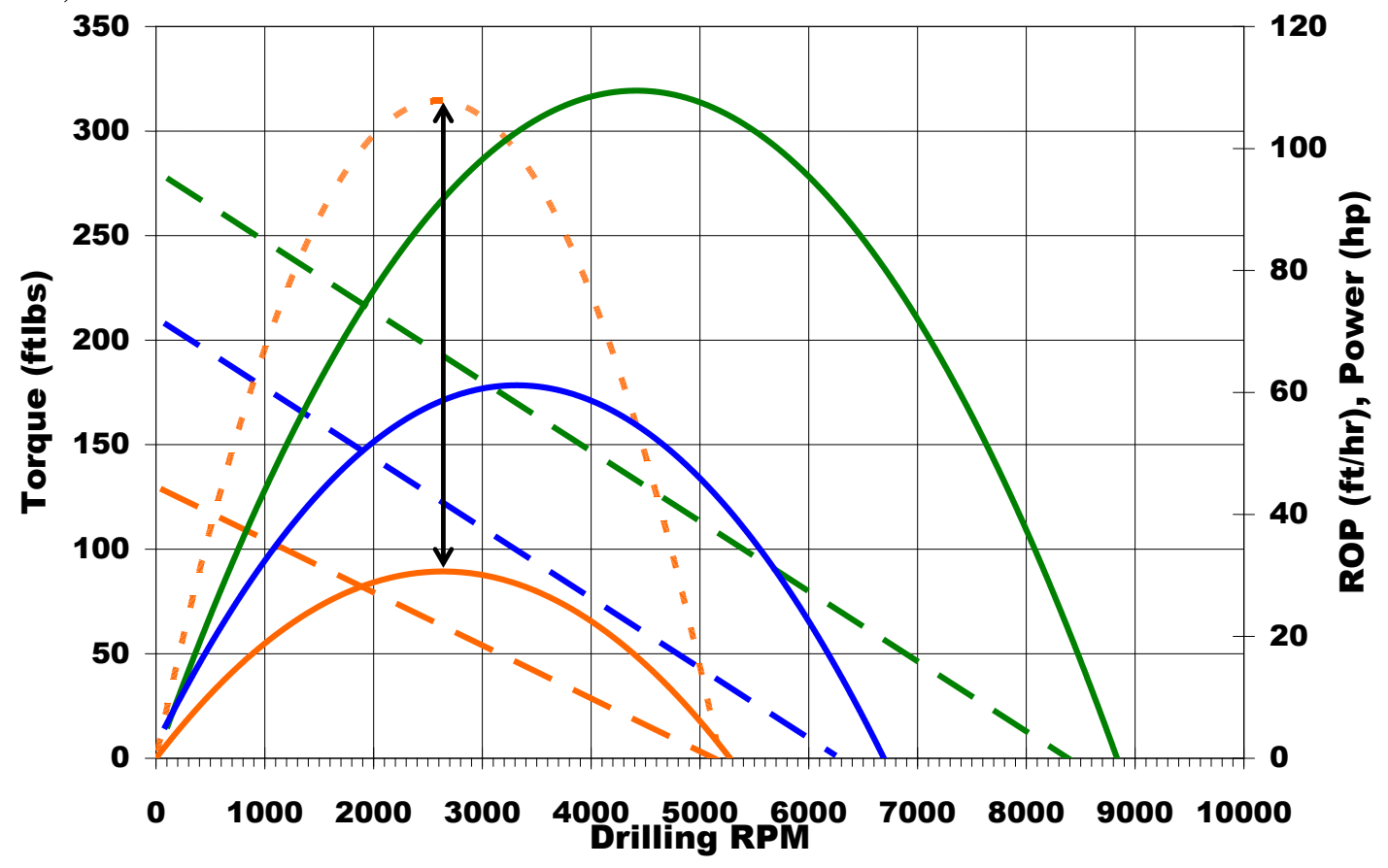

Figure 40: Test 3 Turbodrilling Test Data 
As shown in Figure 41 below, because the Turbodrill assembly was misaligned prior to test, there was a drilled borehole off-center from the rock sample axis. Thereafter, there was a good borehole denoting penetration depths where there was an apparent change in color as the flow rate was increased.

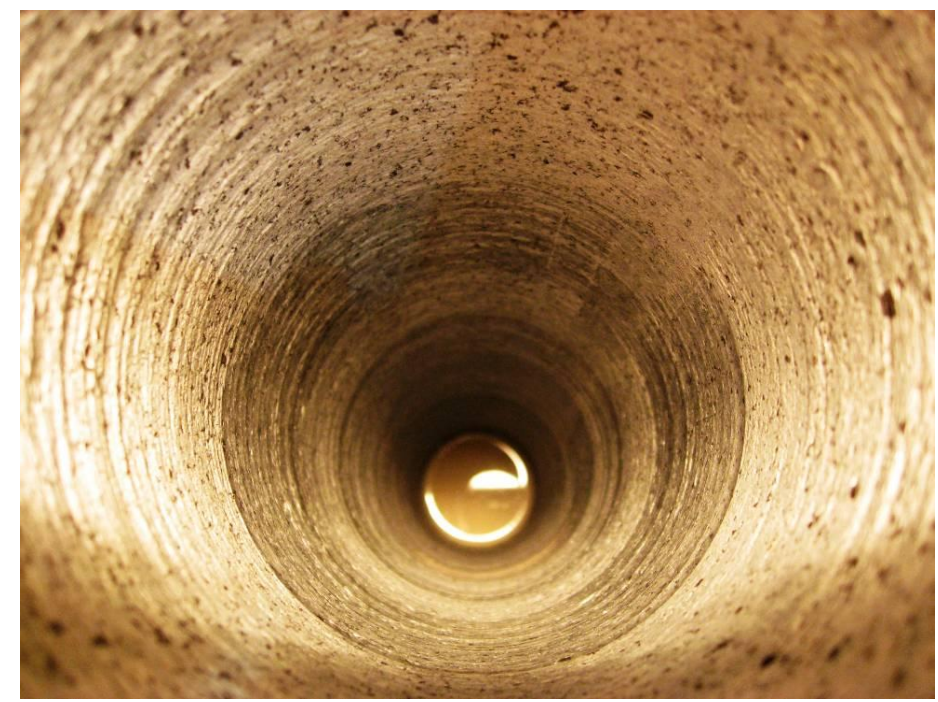

Figure 41: Test 3 Misaligned Borehole

\section{Test 4- NASA Blade Turbodrill Drilling Sandstone with a PDC Drill Bit}

As determined by the data in Figure 42 below, there was a 38\% reduction in RPM with the drill bit shown in Figure 43 when compared to the theoretical value, and an $18 \%$ reduction when compared to the estimated. The torque was $56 \%$ less than theoretical, and $41 \%$ less than the estimated.

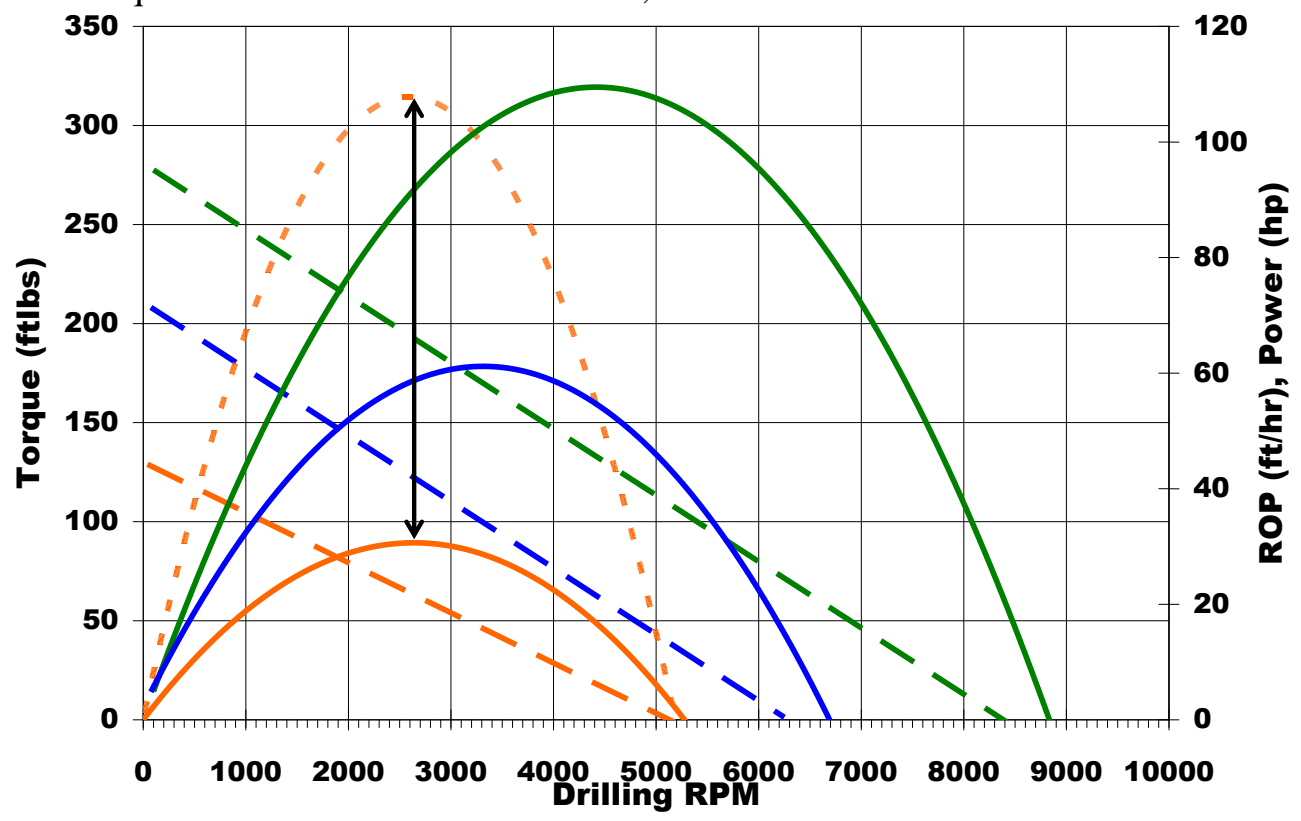

Figure 42: Test 4 Turbodrilling Test Data 


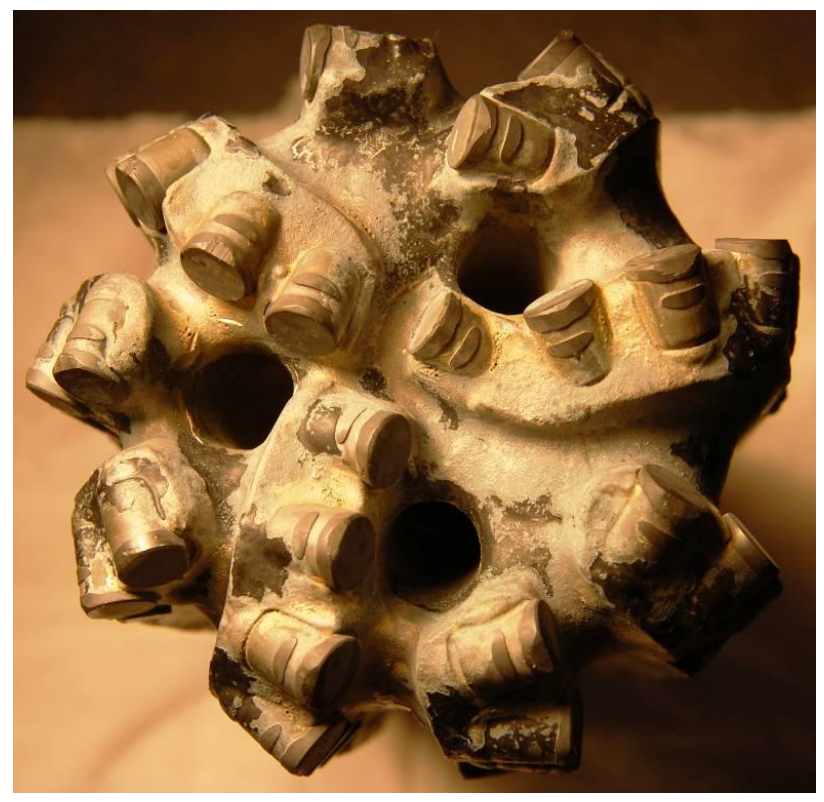

Figure 43: Test 4 Drill Bit After Test

\section{Test 5- HEAT Blade Turbodrill Drilling Granite with an Impregnated Diamond Drill Bit}

As determined by the data in Figure 44 below, there was a $12 \%$ reduction in RPM when compared to the theoretical value, and an $18 \%$ increase when compared to the estimated. The torque was $83 \%$ less than theoretical, and $77 \%$ less than the estimated. The new Heat blades did not perform up to expectation.

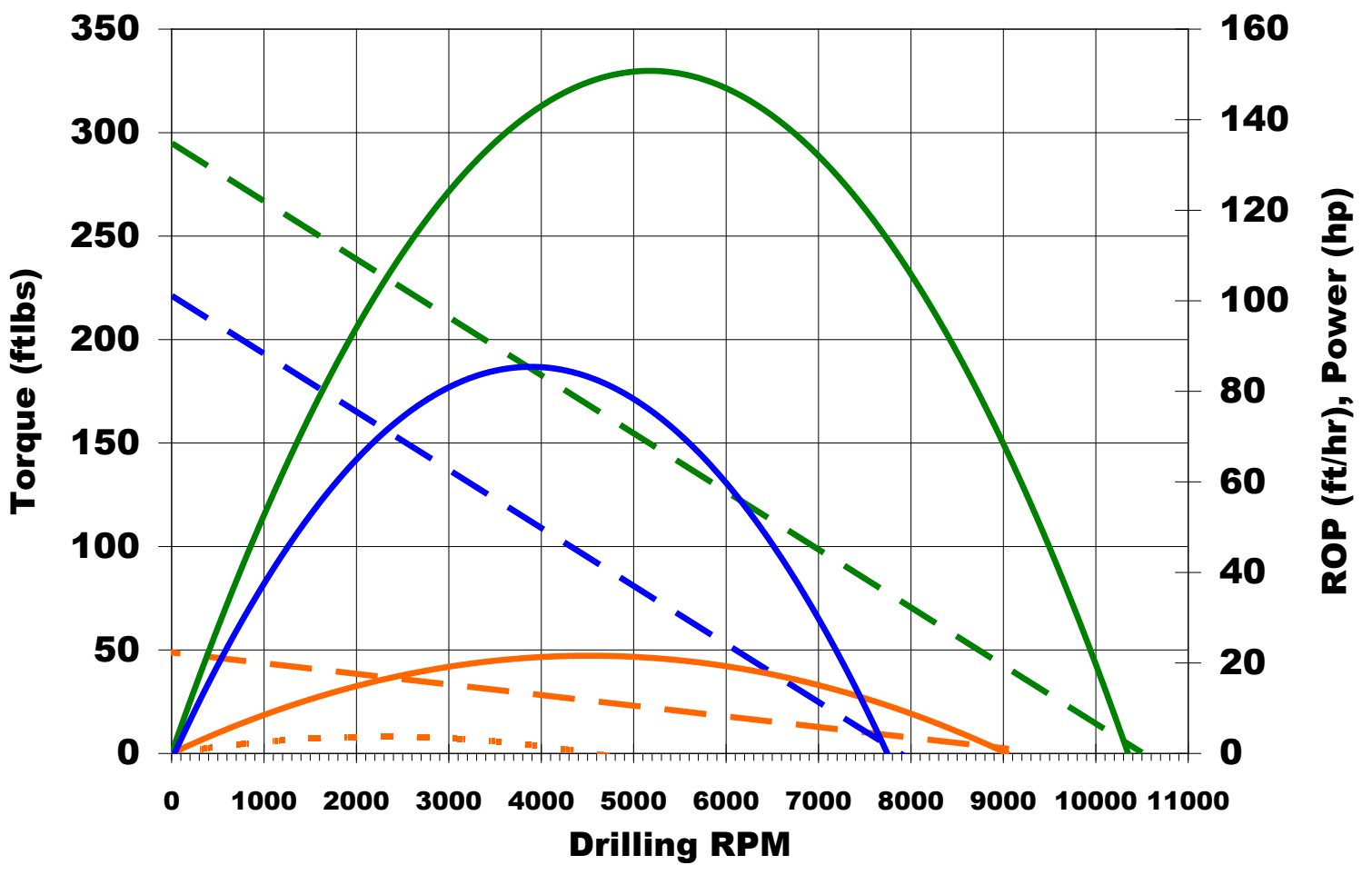

Figure 44: Test 5 Turbodrilling Test Data 
The rock shown in the Figure 45 below shows that prior to Test No. 5 the Turbodrill was misaligned, and thus drilled a borehole that was off-center to the axis of the test rock. However, while the hole was good borehole quality, the pillar on the bottom of the hole indicated bit whirl.

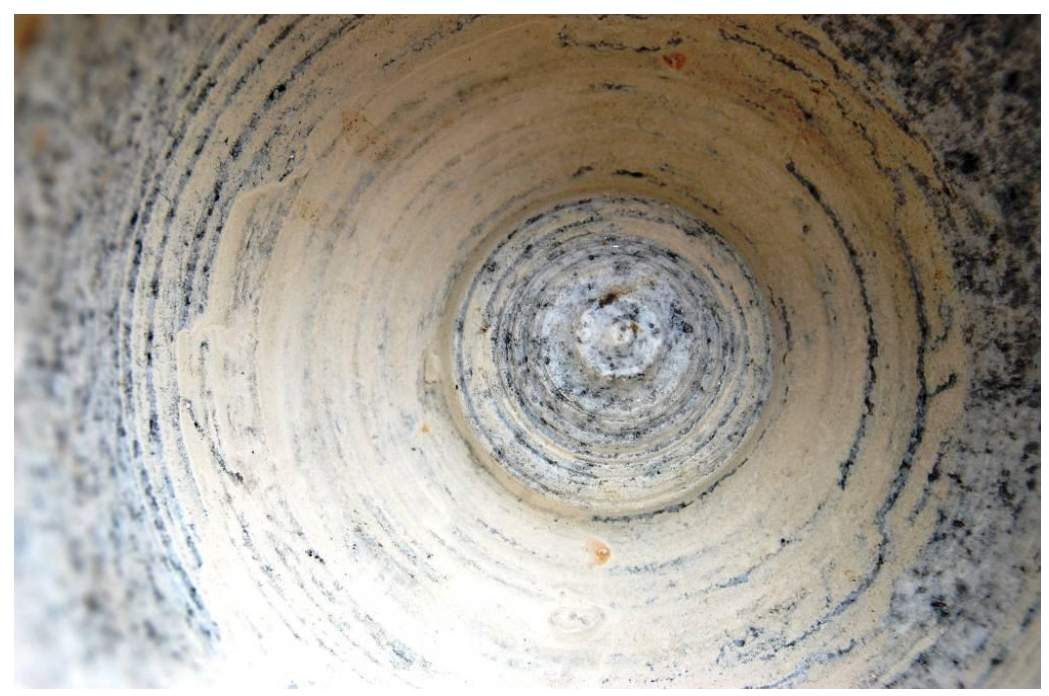

Figure 45: Test 5 Misaligned Borehole

\section{Test 6- HEAT Blade Turbodrill Drilling Sandstone with an Impregnated Diamond Drill Bit}

As determined by the data in Figure 46 below, there was a $49 \%$ reduction in RPM when compared to the theoretical value, and a $31 \%$ increase when compared to the estimated. The torque was $71 \%$ less than theoretical, and $61 \%$ less than the estimated. Again, the new Heat blades did not perform up to expectation.

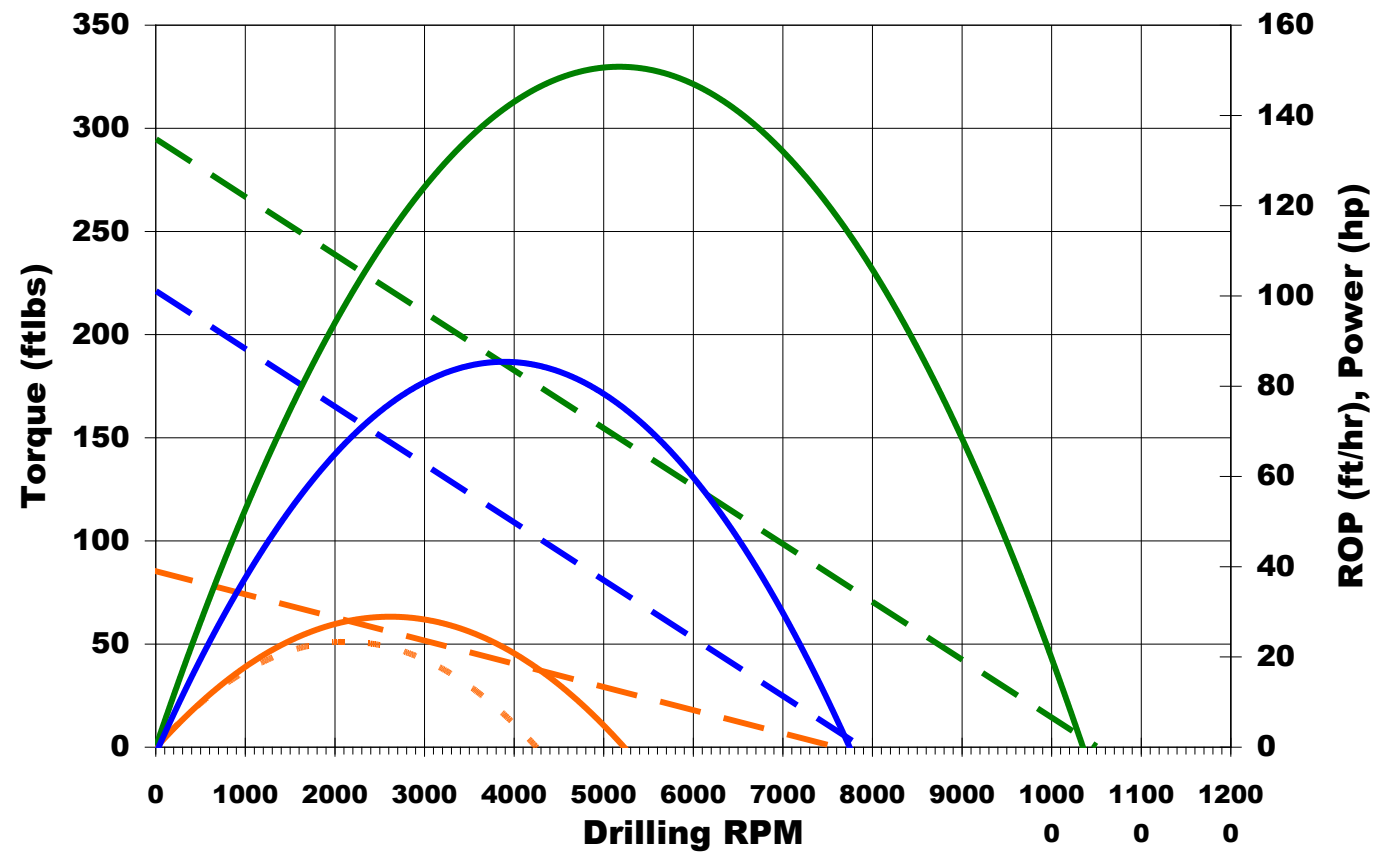

Figure 46: Test 6 Turbodrilling Test Data 
Again, the hole pattern in Figure 47 below showed that the Turbodrill was misaligned prior to test, and then drilled an otherwise perfect hole pattern that was off-center to the axis of the rock. Figure 48 below shows the good condition of the impregnated drill bit after the completion of Test 6 .

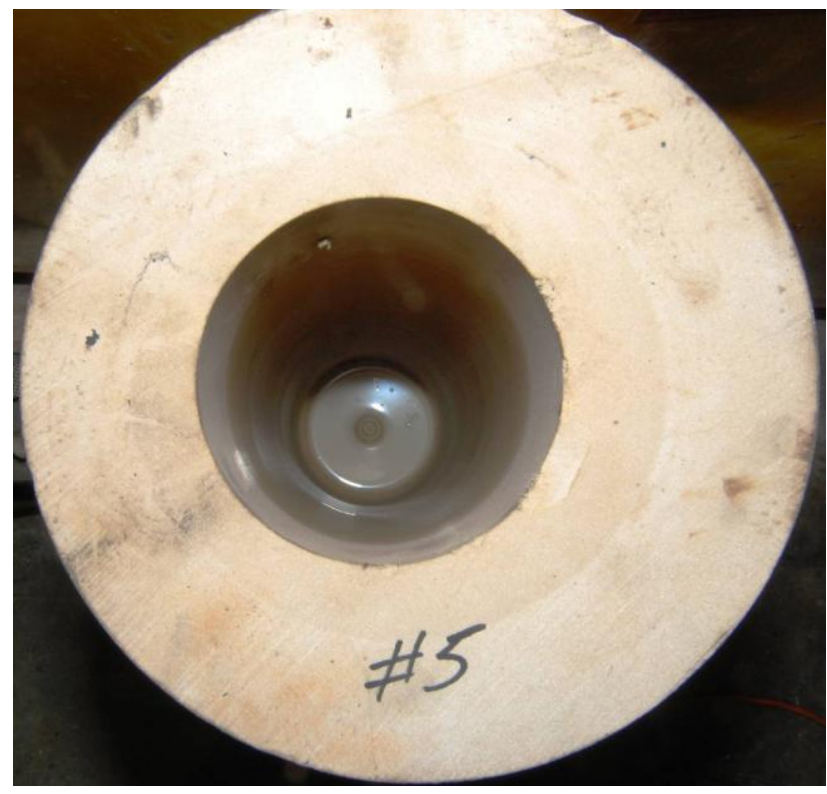

Figure 47: Test 6 Misaligned Borehole

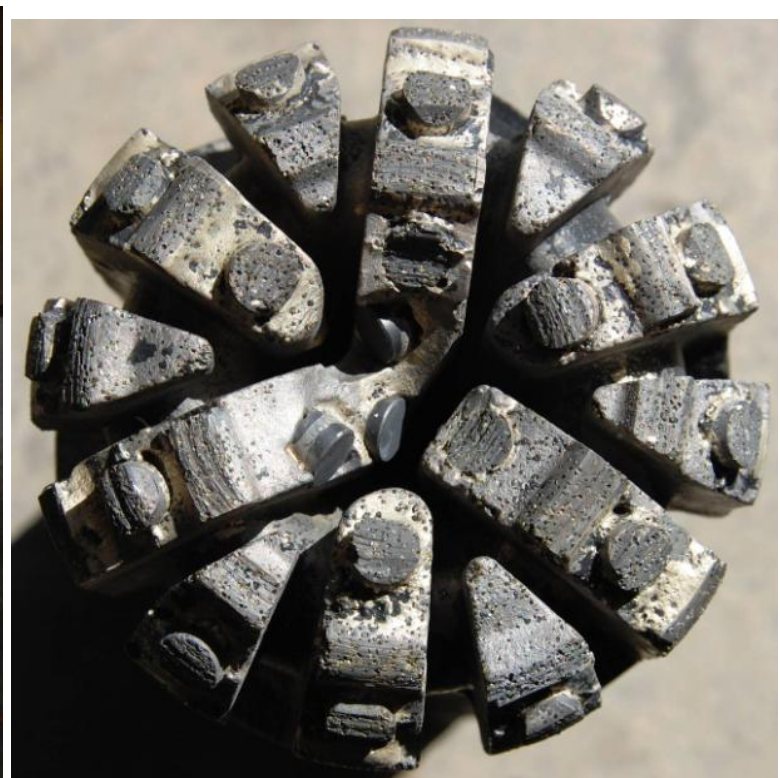

Figure 48: Test 6 Drill Bit After Test

\section{Test 7 and 8 - Heat Turbodrill Drilling Granite and Sandstone with a PDC} Drill Bit

The HEAT Turbodrill suffered a tool failure related to vibration induced loss in compression in the drive train.

\section{Test 9 and 10 - The Commercial Turbodrill Drilling Granite and Sandstone With the Impregnated Diamond Drill Bit}

Delays in setup and with mechanical issues on the rig caused a 3-day over-run and finally resulted in 2 tests not being run.

\section{Test 11 Commercial Mk2 Blade Turbodrill Drilling granite with a PDC Drill Bit}

As determined by the data in Figure 49 below, there was a $63 \%$ reduction in RPM when compared to the theoretical value, and a 51\% increase when compared to the estimated. The torque was $77 \%$ less than theoretical, and $69 \%$ less than the estimated. Again, the new Heat blades did not perform up to expectation. 


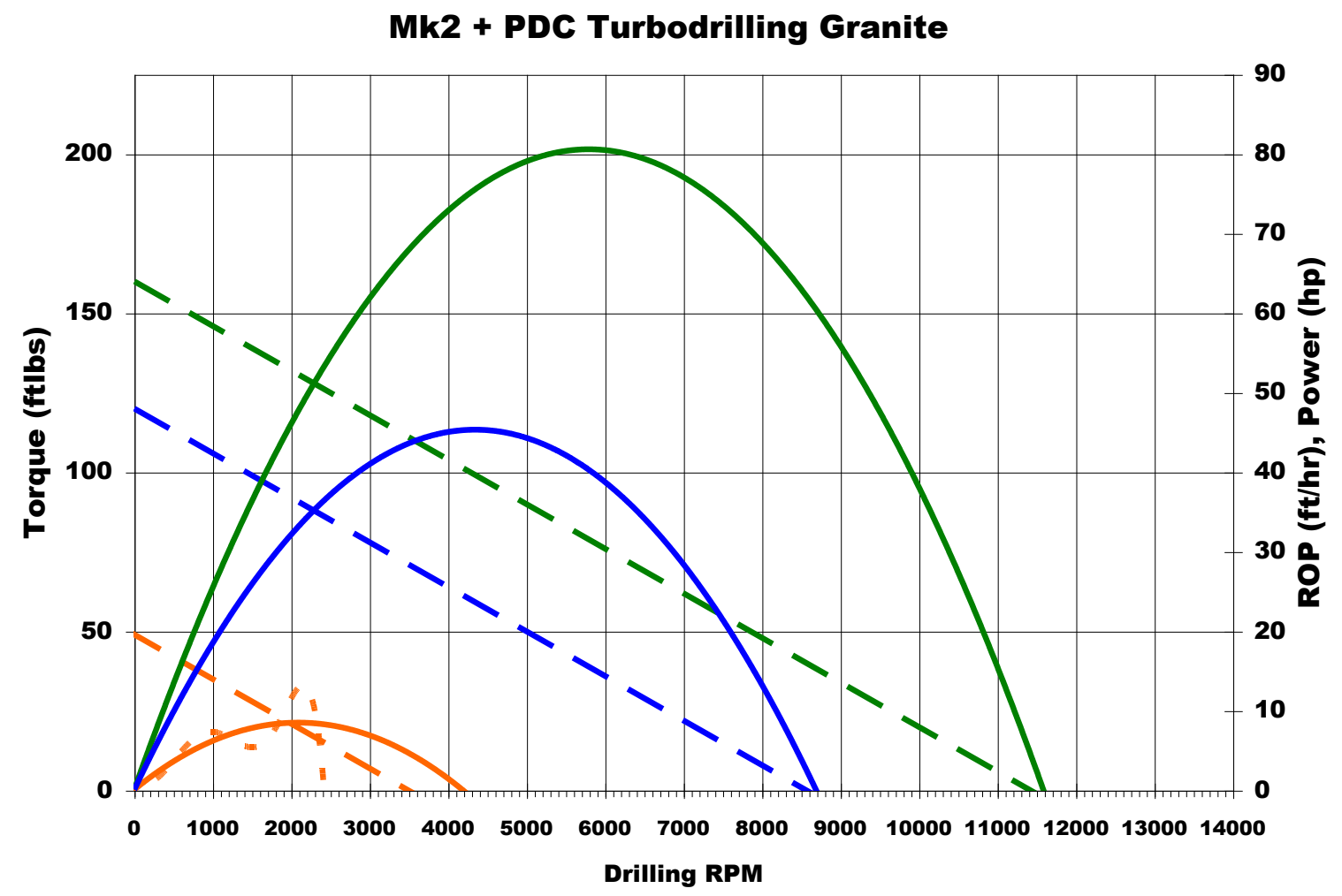

Figure 49: Test 11 Turbodrilling Test Data

The hole quality for Test 11 was perfect as shown in Figure 50 below.

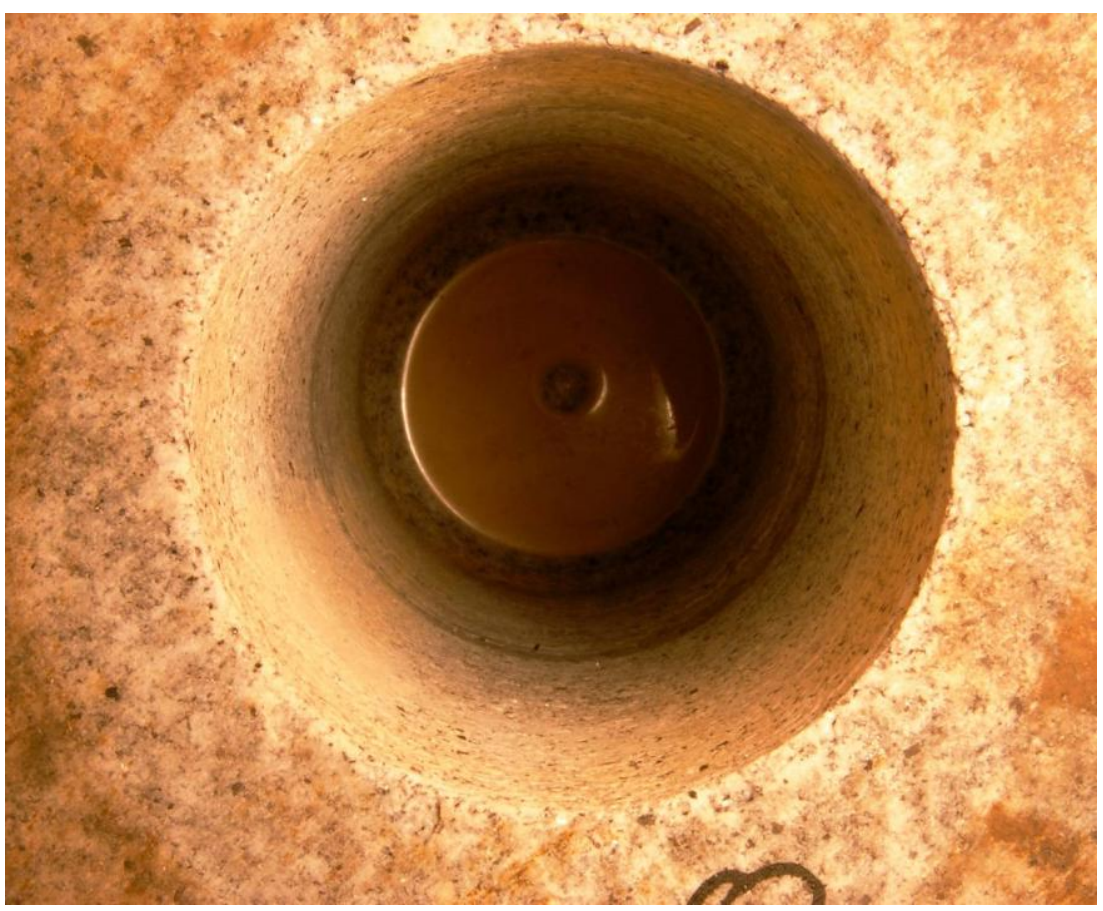

Figure 50: Test 11 Nearly Perfect Borehole 


\section{Test 12 Commercial Blade Turbodrill Drilling sandstone with a PDC Drill Bit}

As determined by the data in Figure 51 below, there was a $46 \%$ reduction in RPM when compared to the theoretical value, and a $31 \%$ increase when compared to the estimated. The torque was $71 \%$ less than theoretical, and $61 \%$ less than the estimated. Again, the new Heat blades did not perform up to expectation.

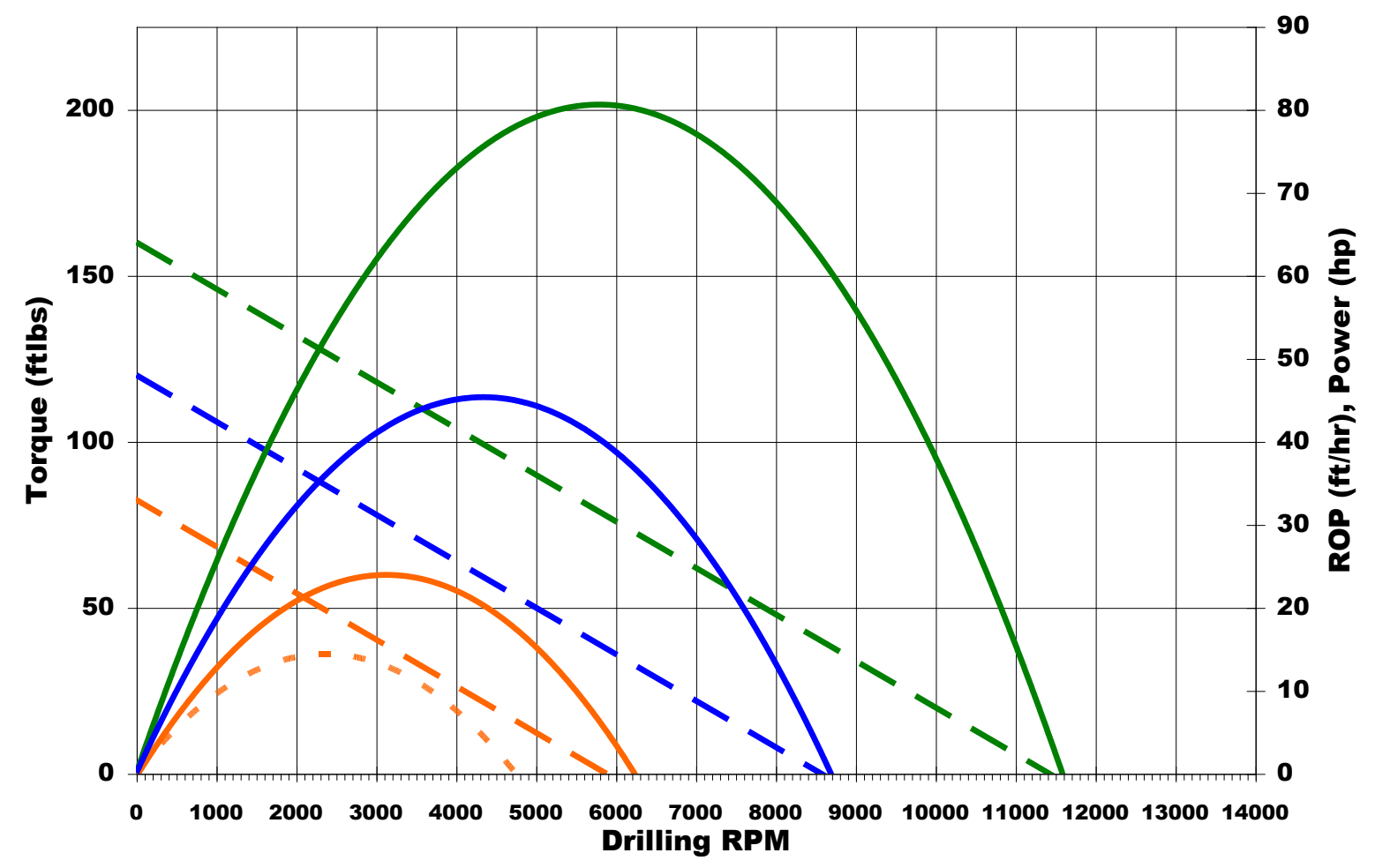

Figure 51: Test 12 Turbodrilling Test Data

\section{Conclusions}

1. Baseline testing of an existing Smith Neyrfor Mk2 in. diameter Turbodrill with polycrystalline diamond compact (PDC) and impregnated diamond drill bits was performed successfully at the Gas Technology Institute Catoosa, OK, field test site.

2. A thermal model, DragBit for PDC and TSP cutters, a modification of the PDCWEAR model developed by the Sandia National Laboratory, has been developed by TII to predict TSP cutter temperatures while drilling hard and abrasive rock at high rpm.

3. The accuracy of thermal profiles for calculated for TSP cutter has been verified by experimental data.

4. Thermal modeling of the TSP cutters revealed an unexpected result: 4-1/8 in drill bits with TSP cutters are able to be rotated at speeds of 2,000 to $4000 \mathrm{rpm}$ without excessive wear.

5. Because of their desirable thermal properties, the TSP cutters developed by TII can be cooled, and thus operate at a lower temperature when compared with the commercial PDC cutter. 
6. New NASA designed blades, the result of basic research was performed at the NASA Ames Research Center, Mountain View, CA, using evolutionary algorithms, response surface methodology, and geometry modeling and the associated codes, provided measureable improvement of the hydraulic efficiency of the NASA prototype Turbodrill.

7. The NASA blade design resulted in a shorter Turbodrill which is desirable for directional drilling.

8. Flow tests run by Smith Neyrfor indicated that the efficiency of the NASA designed blades are 80 to 90\%, which compares to 55\% for the Standard Smith Neyrfor Mk2 Turbodrill. blades used in Turbodrills for the past 30 years.

9. Laboratory Testing at the TerraTek Drilling Laboratory showed that at 2200 to $4000 \mathrm{rpm}$ the NASA Turbodrill generated an average $13 \%$ increase in hydraulic efficiency and a $29 \%$ increase in power.

10. The new Smith Neyrfor Heat blades did not perform up to expectation.

11. Rates of penetration with the PDC-TSP fixed cutter drill bit in sandstone and white sierra granite increased in proportion to the increase in power provided by the NASA designed blades.

12. Turbodrilling tests conducted in Crab Orchard sandstone with the impregnated drill bit showed a significant increase in ROP with increasing WOB and rotary speed. However, the ROP decreased with increasing WOB while drilling White Sierra Granite.

13. The DragBit Model estimate of long term wear rates of the drill bit cutters was verified with the inspection of the fixed cutter bit tested at Terra Tek.

14. The improved performance of the NASA blades can lead to additional advances for the design higherpower Turbodrills.

15. Design improvements have been incorporated into a new downhole drilling assembly for a microhole drilling system.

16. The NASA blade Turbodrill is available to microhole project partners for independent field applications in re-entry wells and workover operations using commercial coiled tubing rigs. 


\section{References}

1. Seale, R. Smith Neyrfor, T. Beaton-Sii-Neyrfor, D. Conroy-Smith Bits, C. Hoffmaster-GeoDiamond, "Turbodrill and High Speed Bit Analysis in Extreme Drilling Applications,",2004 DEA Workshop "Step Changes in Drilling Technology 2004," Moody Gardens, Galveston, Texas, June 22-23, 2004.

2. Seale, R, Smith Neyrfor, T. Beaton-Smith Neyrfor, D. Conroy-Smith Bits, C. HoffmasterGeoDiamond, "Turbodrill and High Speed Bit Analysis in Extreme Drilling Applications,"

DEA Workshop, June 22-23, 2004.

3. Seale, R. Smith Neyrfor, T. Beaton-Smith Neyrfor, D. Conroy-Smith Bits, C. HoffmasterGeodiamond, “Technology Tackles Drilling Challenges,” The Reporter, pp. 106 to 111, July 2005

4 Terra Tek, A Schlumberger Company, "Smaller Footprint Drilling System for Deep and Hard Rock environments; Feasibility of Ultra-High -Speed Diamond Drilling," DOE Award No.: DE-FE2603NT15401, dated August 5, 2009.

5 Glowka, David, Technology International, Inc., "DragBit Users' Guide, PDC and TSP Fixed Cutter Drill Bit Design Software Drill Bit Performance, Cutter Temperature, and Wear," August 22, 2007. 


\section{Acknowledgements}

Technology International, Inc. wants to recognize the contributions of the Principal Investigator, Robert P. Radtke, and project participants David A. Glowka, Sheila Unterreiner, and Virlen Wagner, Technology International, Inc.; Dr. Man Mohan Rai, NASA Ames Research Laboratory; David Conroy, Dan Sarik, Rocky Seale, Joseph Hanna, Smith Neyrfor, Dr. Anthony Griffo, Smith Bits; and Homer Robertson, Terra Tek Drilling Laboratory. The investigation was performed with funding from the United States Department of Energy National Energy Technology Laboratory (DOE NETL), plus cost sharing from Smith Neyrfor and Technology International, Inc. We especially want to recognize Virginia Weyland and Roy Long, DOE NETL, for their guidance and support. 


\section{List of Acronyms}

\begin{tabular}{|c|c|}
\hline$\%$ & percent \\
\hline $\mathrm{C}$ & Centigrade \\
\hline Co & Cobalt \\
\hline $\mathrm{D}$ & Depth \\
\hline $\mathrm{CM}$ & Centimeter \\
\hline DOC & Depth of Cut \\
\hline DOE & U.S. Department of Energy \\
\hline $\mathrm{E}$ & Exponent \\
\hline $\mathrm{F}$ & Fahrenheit and Force \\
\hline FE & Finite Element Model \\
\hline FFT & Fast Fourier Transfer \\
\hline $\mathrm{Ft}$ & Feet \\
\hline GPM & Gallons per minute \\
\hline GTI & Gas Technology Institute \\
\hline GUI & Graphical User Interface \\
\hline $\mathrm{H}$ & Height \\
\hline HR & Hour \\
\hline $\mathrm{Lb}$ & Pound \\
\hline HS & High Speed Drill Bit \\
\hline $\mathrm{Hz}$ & Hertz \\
\hline ID & Inside Diameter \\
\hline In & Inch \\
\hline K & Kilo \\
\hline $\mathrm{L}$ & Length \\
\hline M & Meter \\
\hline MCTR & Microhole Coiled Tubing Rig \\
\hline MTBF & Mean Time Between Failure \\
\hline Mk2 & Mark 2 Turbodrill \\
\hline MT & Microhole Technology \\
\hline PDC & Polycrystalline Diamond Cutter \\
\hline Q & Heat Flux \\
\hline ROP & Rate of Penetration \\
\hline
\end{tabular}




$\begin{array}{ll}\text { RPM } & \text { Revolutions per Minute } \\ \text { SCFM } & \text { Standard Cubic Feet per Minute } \\ \text { T } & \text { Temperature or Torque } \\ \text { TII } & \text { Technology International, Inc. } \\ \text { TSP } & \text { Thermally Stable Diamond } \\ \text { V } & \text { Velocity } \\ \text { VSP } & \text { Vertical Seismic Profiling } \\ \text { W } & \text { Watts } \\ \text { WC } & \text { Tungsten Carbide } \\ \text { WOB } & \text { Weight on Bit }\end{array}$




\title{
NETL AAD DOCUMENT CONTROL \\ BLDG. 921 \\ U. S. DEPARTMENT OF ENERGY \\ NATIONAL ENERGY TECHNOLOGY LABORATORY \\ P. O. BOX 10940 \\ PITTSBURGH, PA 15236-0940
}

\author{
626 Cochrans Mill Road \\ P.O. Box 10940 \\ Pittsburgh, PA 15236-0940 \\ 3610 Collins Ferry Road \\ P.O. Box 880 \\ Morgantown, WV 26507-0880 \\ 1450 Queen Avenue SW \\ Albany, OR 97321-2198 \\ 2175 University Ave. South \\ Suite 201 \\ Fairbanks, AK 99709
}

National Energy Technology Laboratory

Visit the NETL website at:

www.netl.doe.gov

Customer Service:

1-800-553-7681 